\title{
Synthesis of Fused Imidazole-Containing Ring Systems via Dual Oxidative Amination of $\mathrm{C}\left(\mathrm{sp}^{3}\right)-\mathrm{H}$ bonds
}

Georgette Castanedo, * Yanzhou Liu, James J. Crawford and Marie-Gabrielle Braun Discovery Chemistry, Genentech, Inc., South San Francisco, CA 94080

\section{SUPPORTING INFORMATION}

Table of Contents

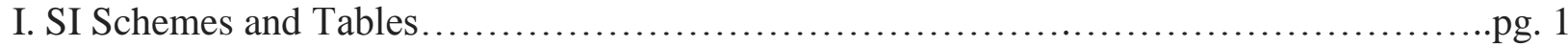

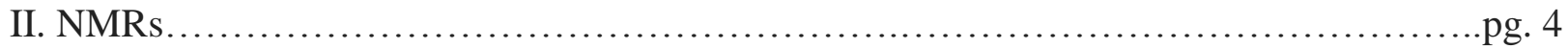

Reaction Optimization using ethyl 2-thiazol-2-ylacetate and 3-bromobenzylamine:

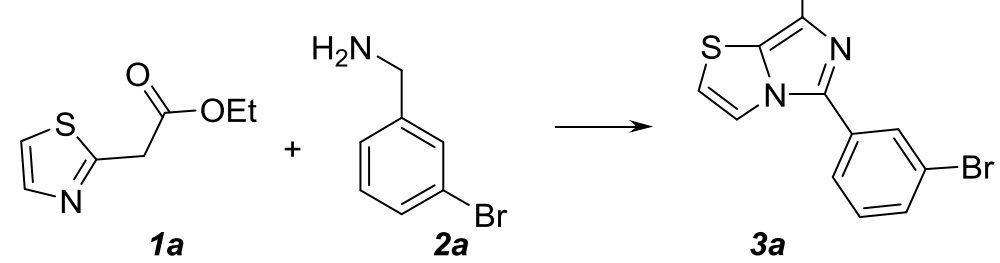

SI Table 1: Halogen Source Optimization

\begin{tabular}{|c|c|c|c|}
\hline Entry & Iodine Source & $\begin{array}{c}\text { Yield of compound } 3 \boldsymbol{a} \\
(\boldsymbol{\%})^{a, b}\end{array}$ & \% conversion of $\mathbf{1 a}$ \\
\hline 1 & Iodine & 64 & 100 \\
\hline 2 & $\mathrm{NIS}$ & 84 & 100 \\
\hline 3 & $\mathrm{Bu}_{4} \mathrm{NI}$ & 23 & 100 \\
\hline 4 & $\mathrm{KI}$ & 25 & 100 \\
\hline
\end{tabular}

${ }^{a}$ Yield of $3 a$, determined by LCMS using naphthalene as a quantitative internal standard.

${ }^{b}$ Correction factor of 1.05 applied to LCMS yields of $3 \boldsymbol{a}$ after determining difference in ratios of 
product to starting material by LCMS/NMR

SI Table 2: Solvent Optimization

\begin{tabular}{|c|c|c|c|}
\hline Entry & Solvent & $\begin{array}{c}\text { Yield of compound 3a } \\
(\%)^{a, b}\end{array}$ & \begin{tabular}{c} 
\% conversion of 1a \\
\hline 1
\end{tabular} \\
\hline 2 & DMA & 85 & 100 \\
\hline 3 & DMF & 87 & 100 \\
\hline 4 & DMSO & 86 & 100 \\
\hline
\end{tabular}

${ }^{a}$ Yield of $\mathbf{3 a}$, determined by LCMS using naphthalene as a quantitative internal standard

${ }^{b}$ Correction factor of 1.05 applied to LCMS yields of $3 a$ after determining difference in ratios of product to starting material by LCMS/NMR

\section{SI Table 3: $\beta$-Keto ester as substrate}<smiles>CCOC(=O)C(=O)c1nccs1</smiles>

$1 w$

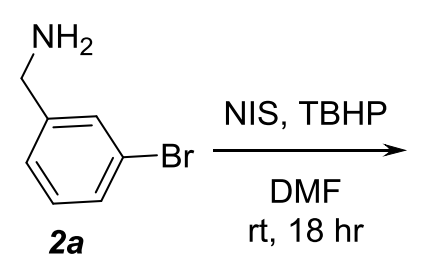

$2 a$<smiles>CCOC(=O)c1nc(-c2cccc(Br)c2)n2ccsc12</smiles>

\begin{tabular}{|c|c|c|c|}
\hline Entry & Substrate & Yield of compound $\mathbf{3 a}(\boldsymbol{\%})^{a, b}$ & \% conversion of $\mathbf{1} \boldsymbol{w}$ \\
\hline 1 & $\mathbf{1} w$ & 89 & 100 \\
\hline
\end{tabular}

${ }^{a}$ Yield of 3, determined by LCMS using naphthalene as a quantitative internal standard

${ }^{b}$ Correction factor of 1.05 applied to LCMS yields of $3 a$ after determining difference in ratios of product to starting material by LCMS/NMR 
SI Table 4: Control Experiments

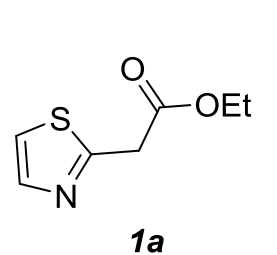

$1 a$

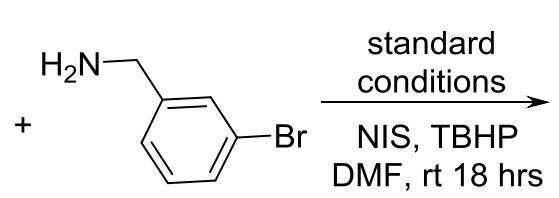

$2 a$

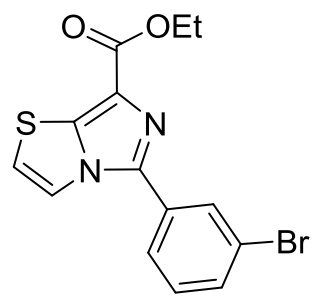

$3 a, 87 \%{ }^{a, b}$

\begin{tabular}{|c|c|c|c|c|}
\hline $1 a$ & + & no amine & $\begin{array}{c}\text { standard } \\
\text { conditions }\end{array}$ & [O] of 1 \\
\hline $1 a$ & + & $2 a$ & $\begin{array}{c}\begin{array}{c}\text { standard } \\
\text { conditions }\end{array} \\
\text { MINUS NIS }\end{array}$ & no product \\
\hline $1 a$ & + & $2 a$ & 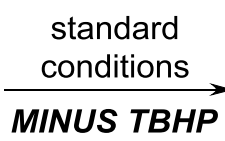 & $3 a, 59 \%{ }^{a, b}$ \\
\hline
\end{tabular}

\begin{tabular}{|c|c|c|c|}
\hline Entry & $\begin{array}{c}\text { Reagent } \\
\text { Missing }\end{array}$ & Yield of compound 3a $(\boldsymbol{\%})^{a, b}$ & \% conversion of 1 \\
\hline 1 & No Amine & 0 & $95^{c}$ \\
\hline 2 & No NIS & 0 & 72 \\
\hline 3 & No TBHP & 59 & 75 \\
\hline
\end{tabular}

${ }^{a}$ Yield of $\mathbf{3 a}$, determined by LCMS using naphthalene as a quantitative internal standard

${ }^{b}$ Correction factor of 1.05 applied to LCMS yields of $3 a$ after determining difference in ratios of product to starting material by LCMS/NMR

${ }^{c}$ Mass for oxidation of $\mathbb{l a}$ to $\mathbb{l} \boldsymbol{w}$ was seen by mass spec which is consistent with observations from Mohan, D.; Rao, S.; Ravi, C.; and Adimurthy, S. Org. Biomol. Chem. 2015, 13, 5602. 
NMR Characterization Data

Starting Material 1e
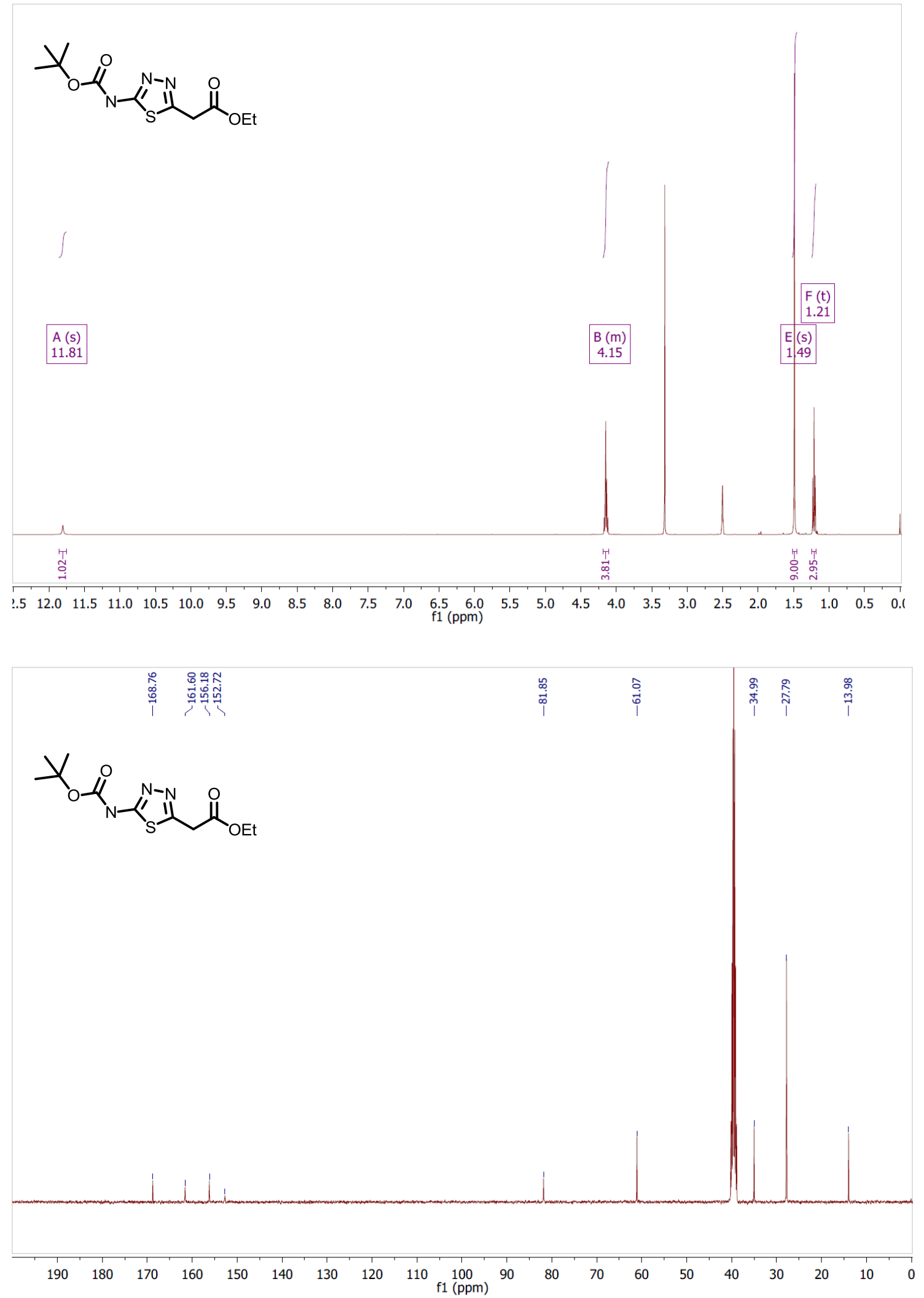


\section{Starting Material $\mathbf{l h}$}
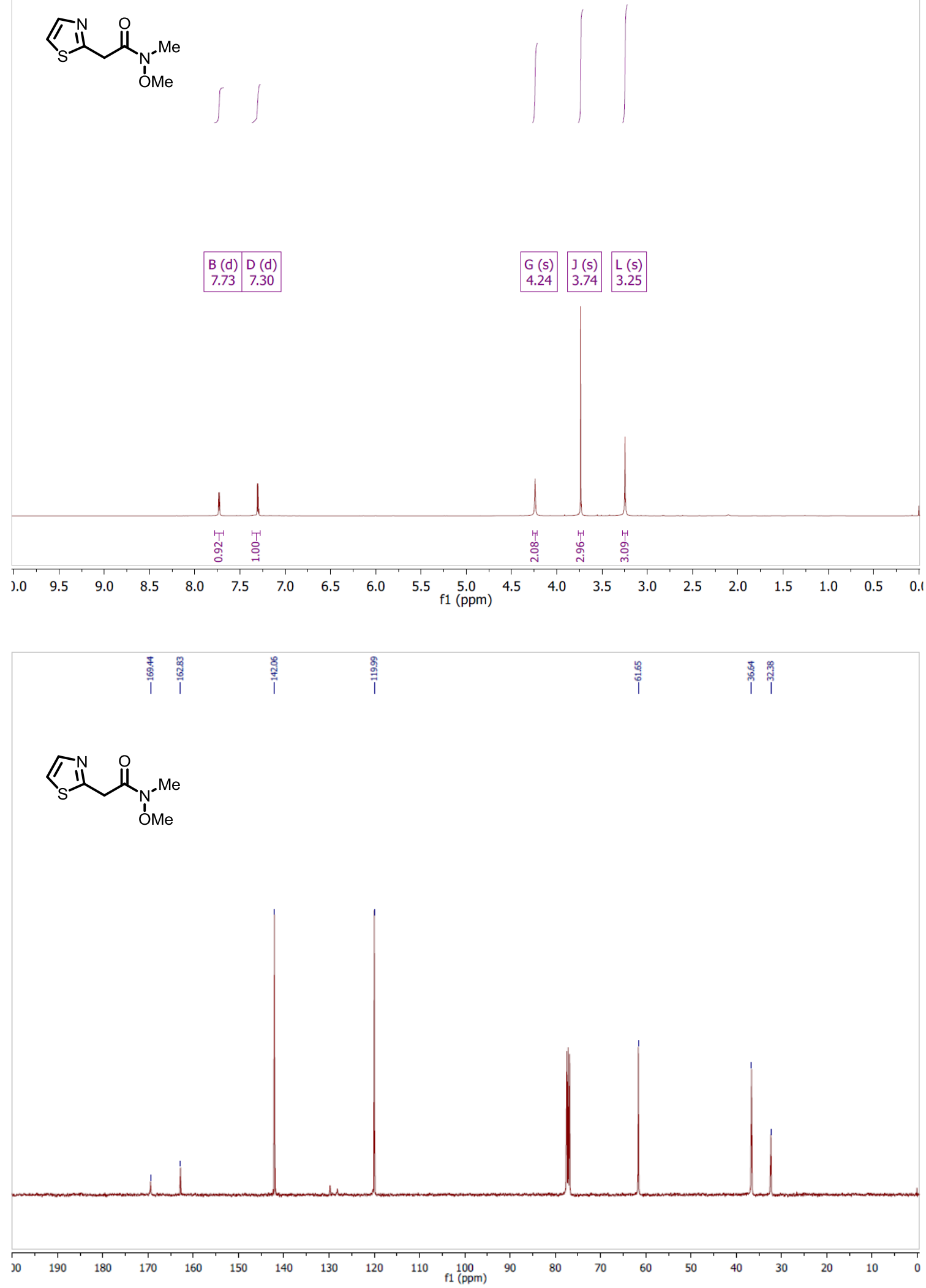


\section{Starting Material $1 p$}
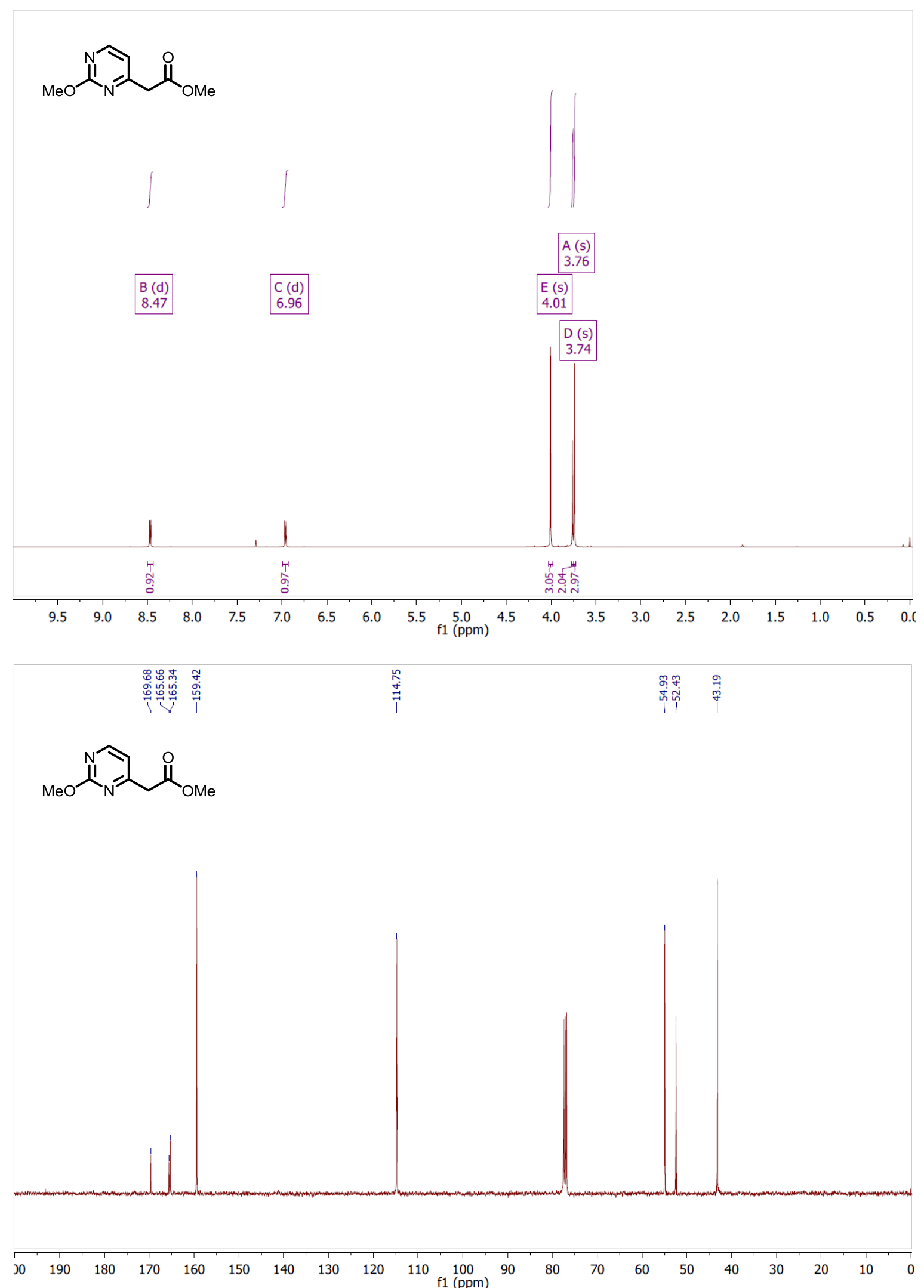


\section{Starting Material $\mathbf{1 q}$}
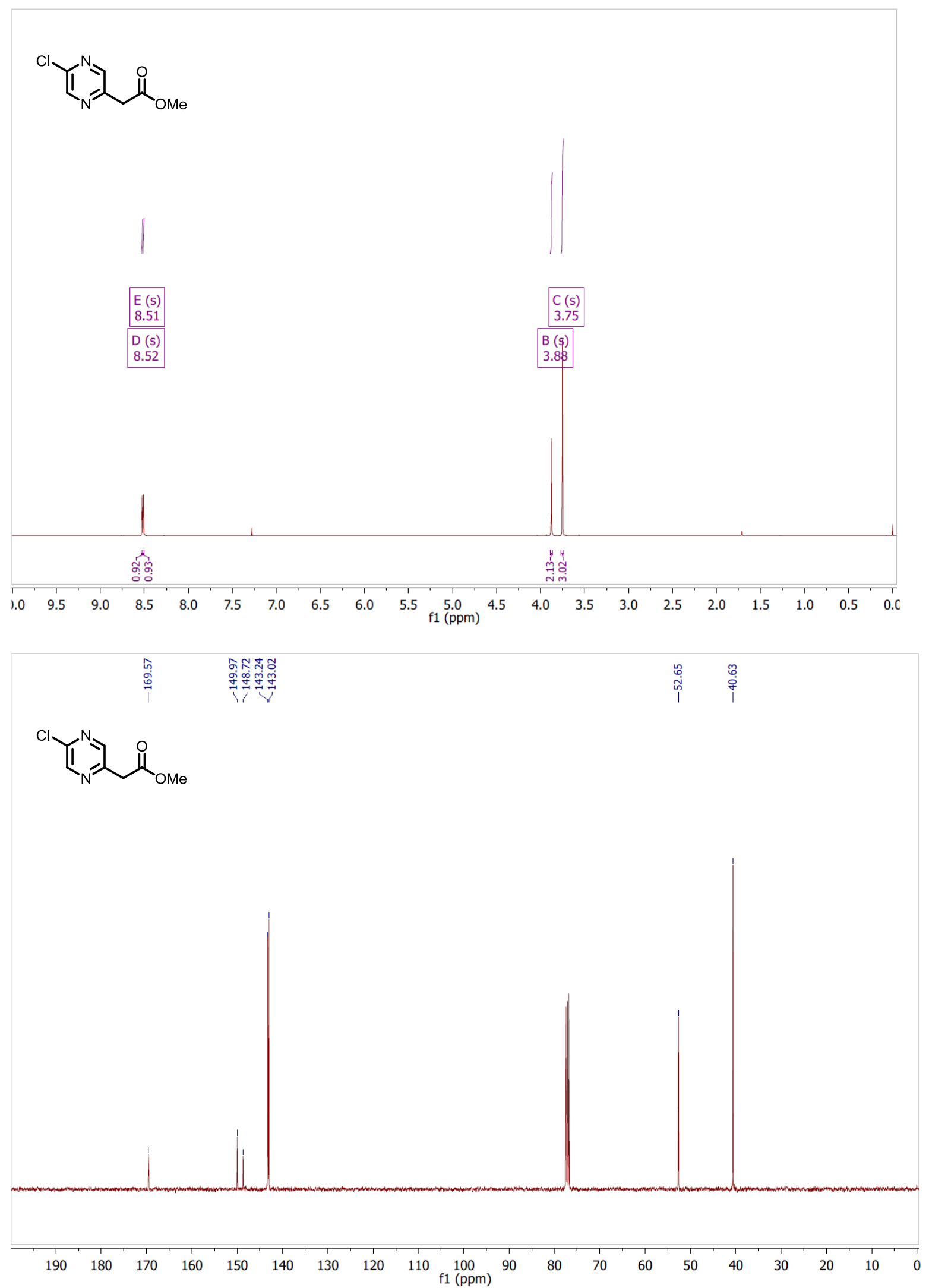


\section{Compound $3 a$}
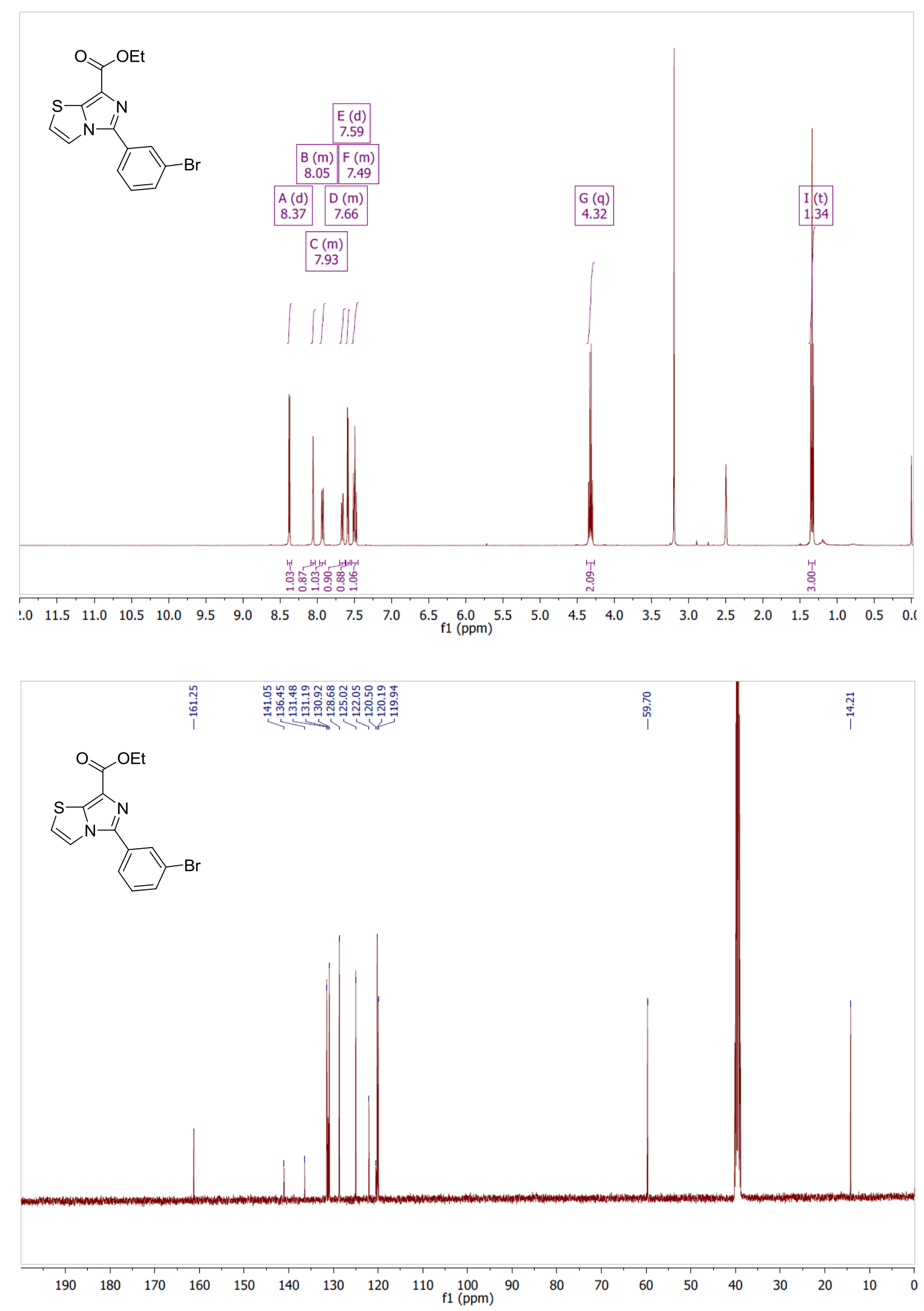


\section{Compound $3 b$}
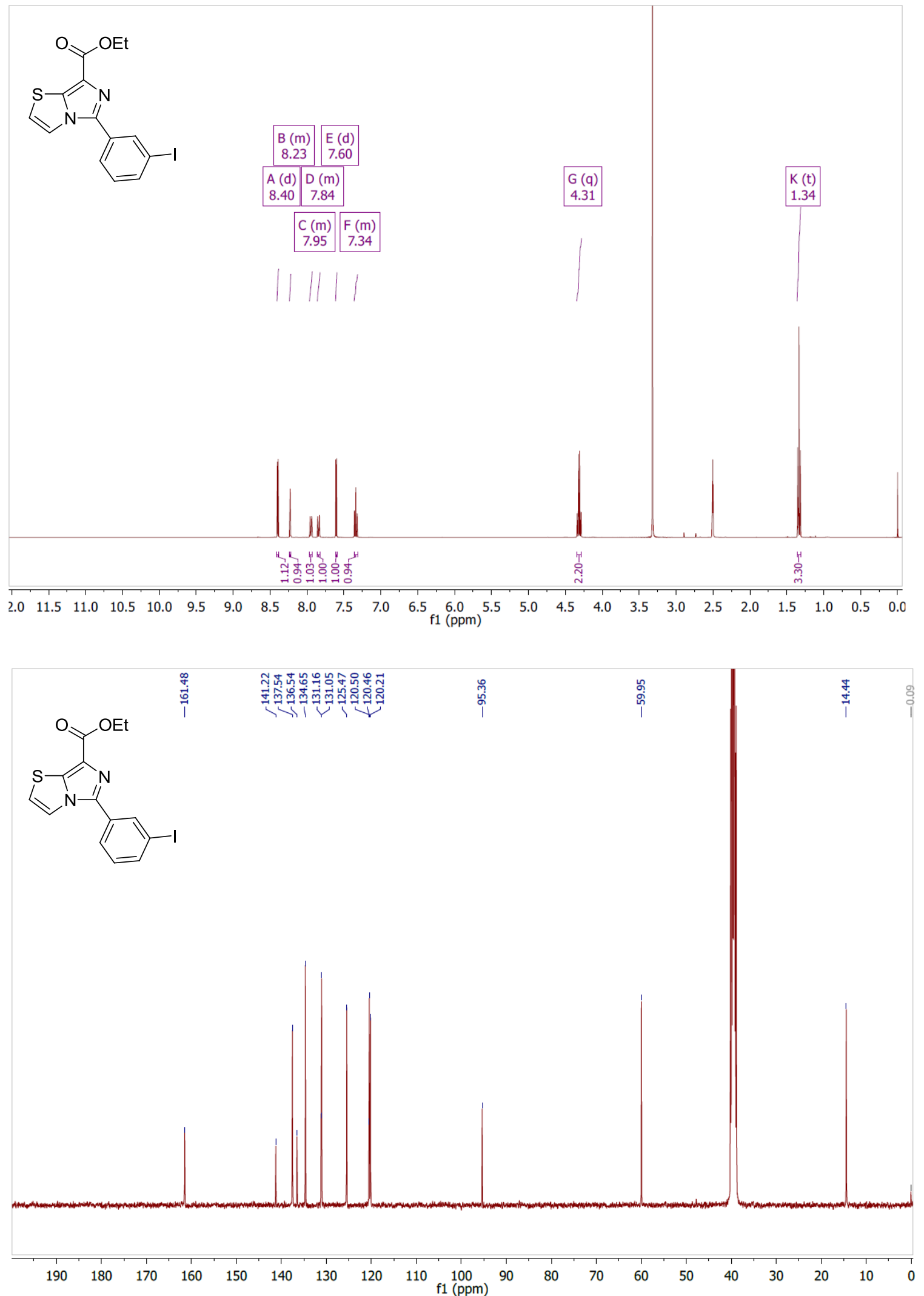


\section{Compound $3 c$}
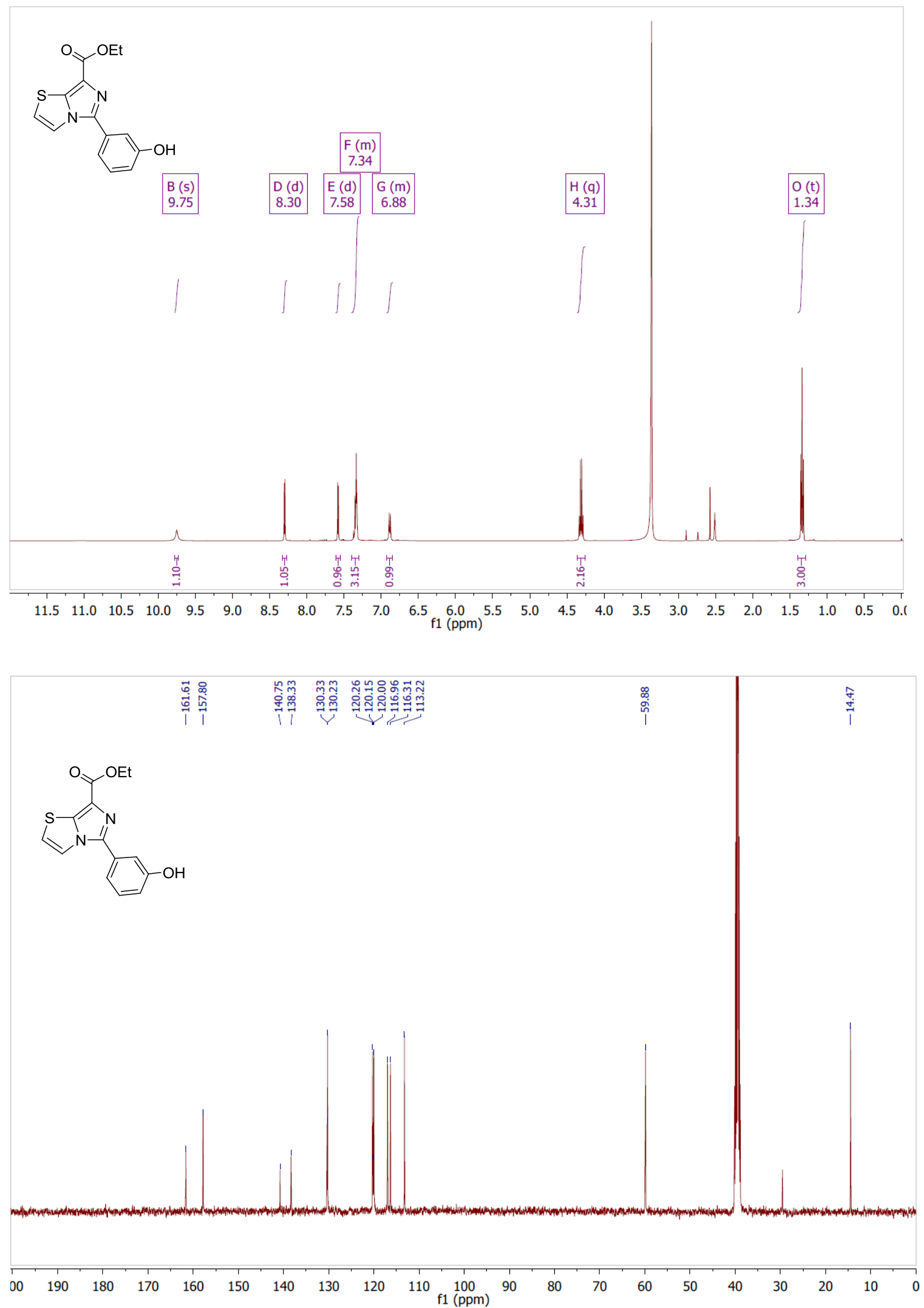


\section{Compound $3 d$}
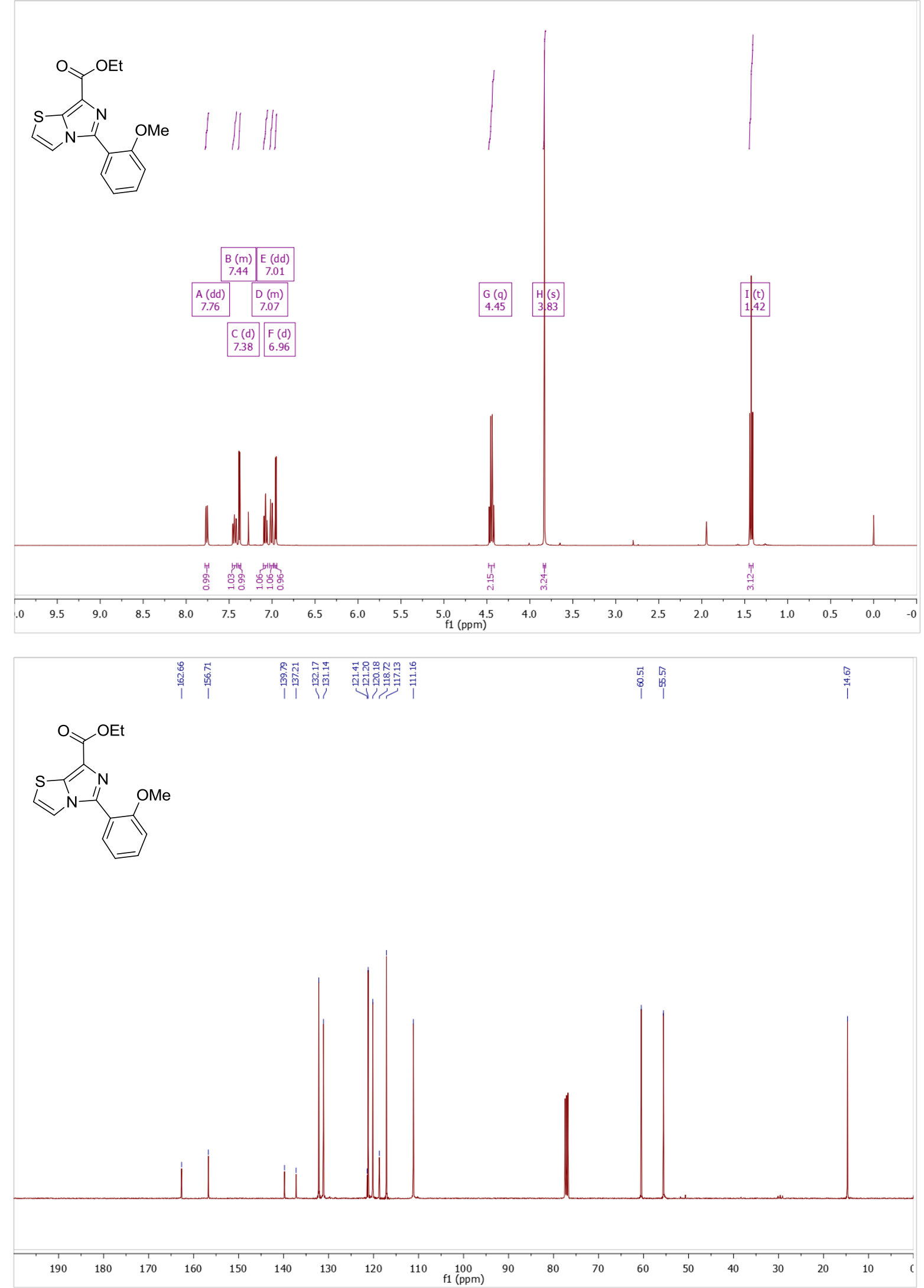


\section{Compound $3 e$}
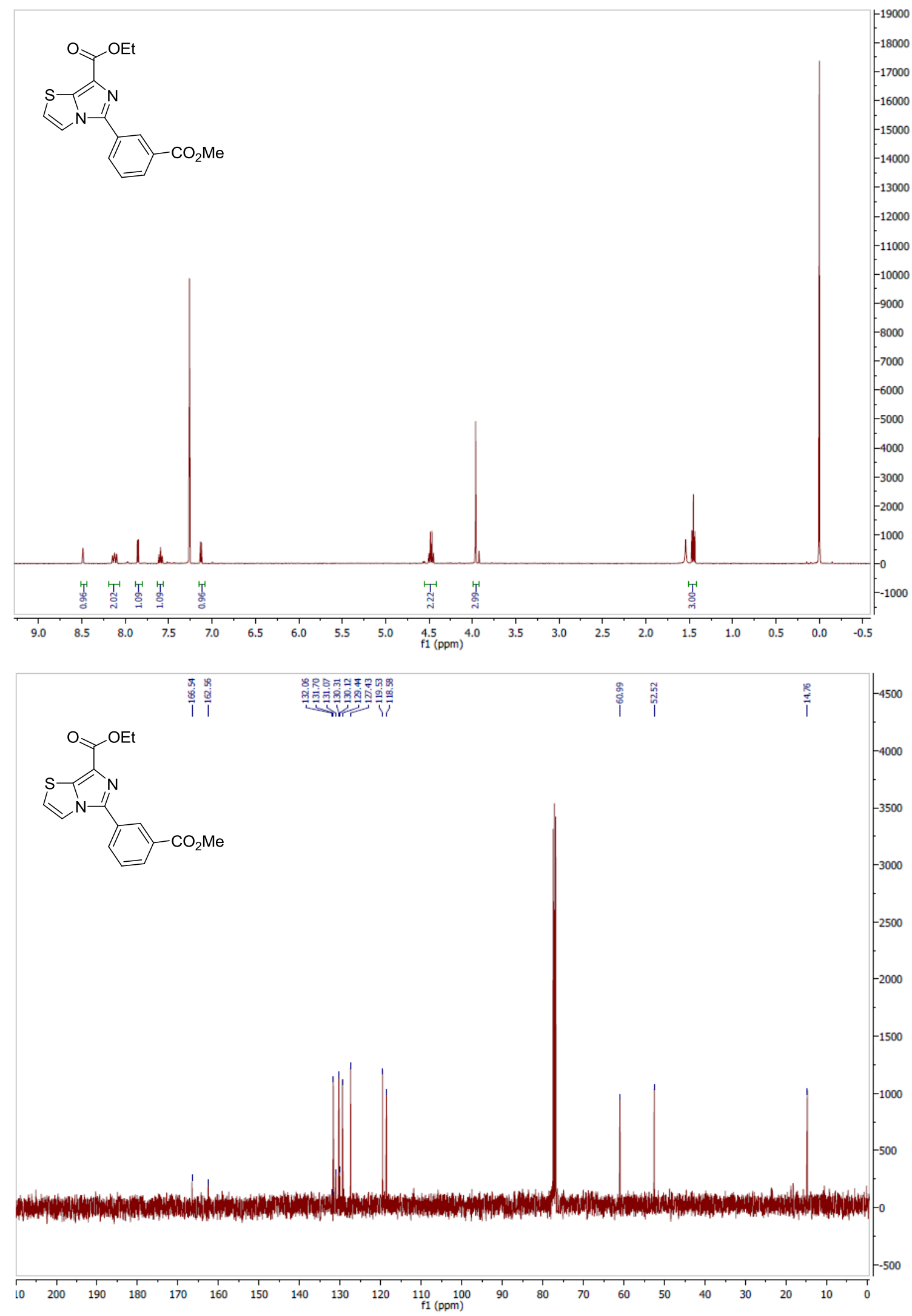


\section{Compound $3 f$}
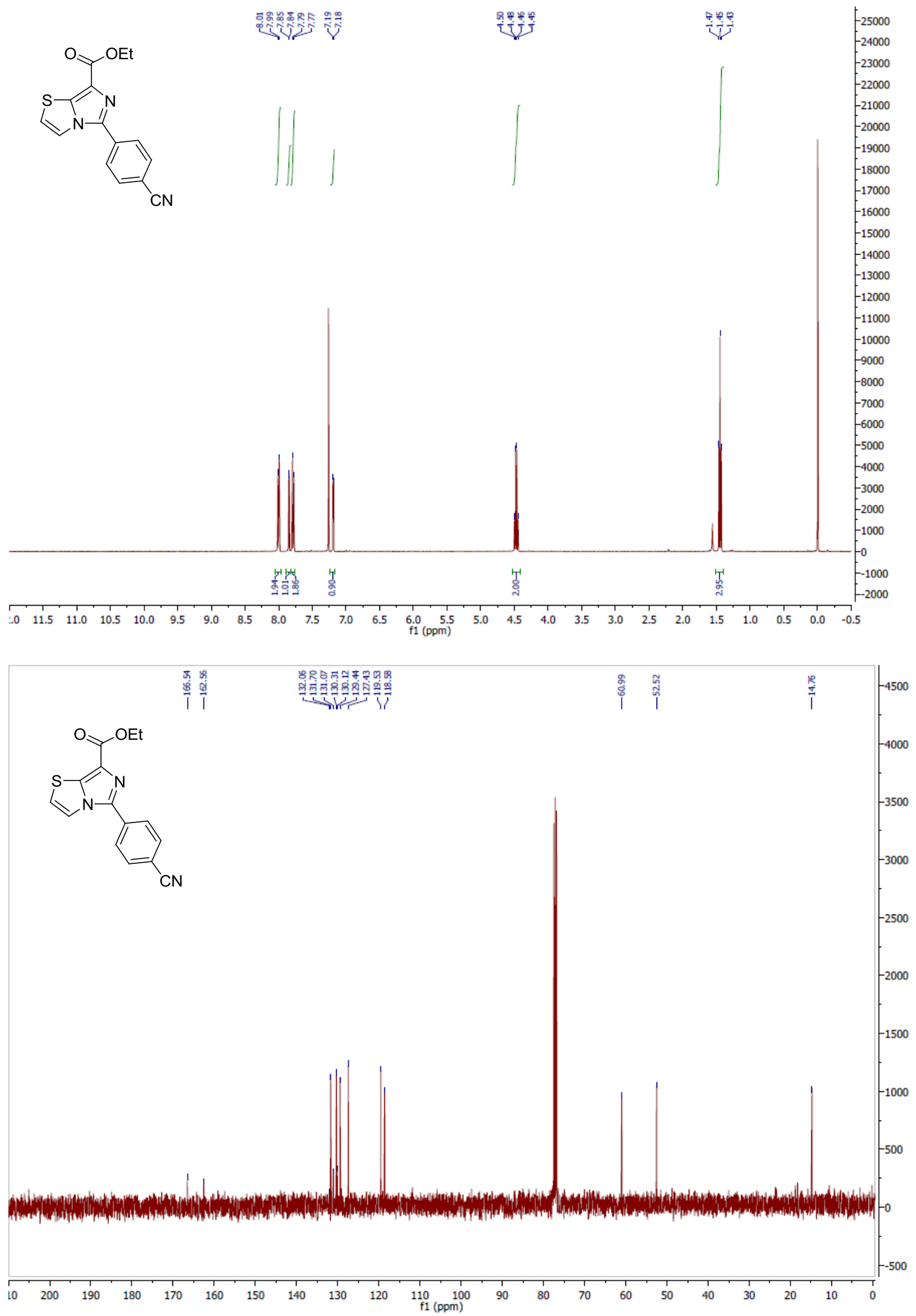


\section{Compound $3 g$}
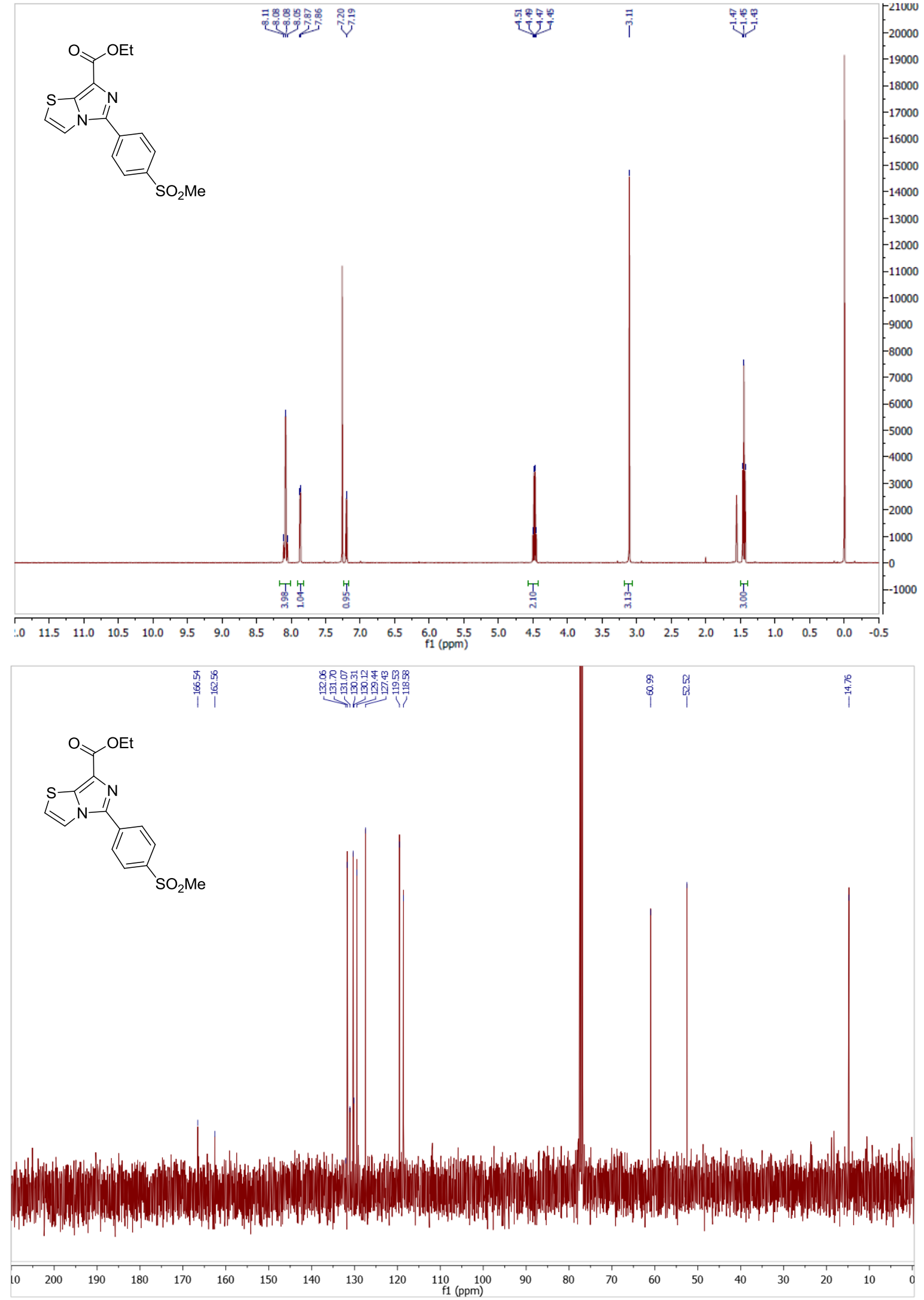


\section{Compound $3 h$}
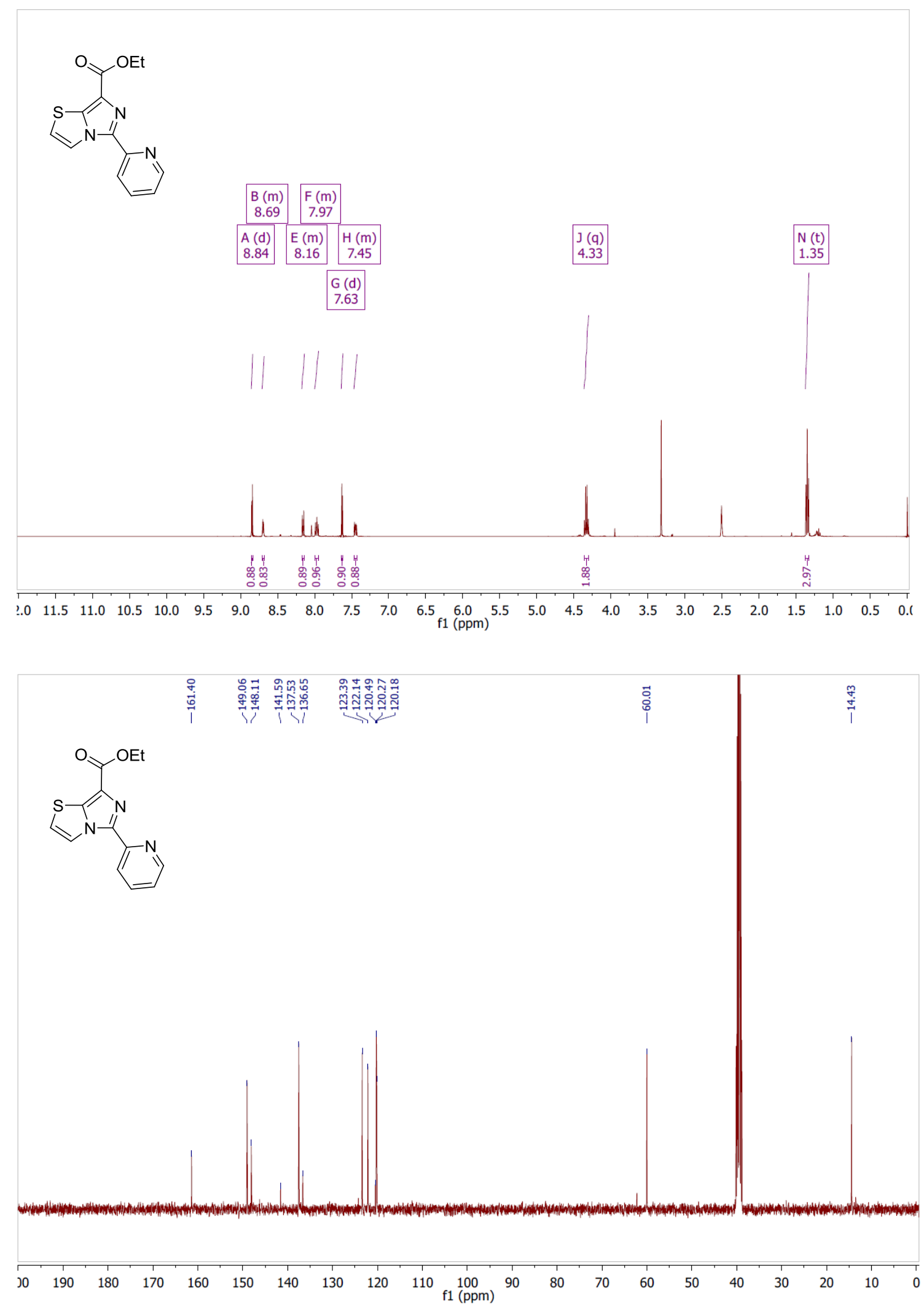


\section{Compound $3 i$}
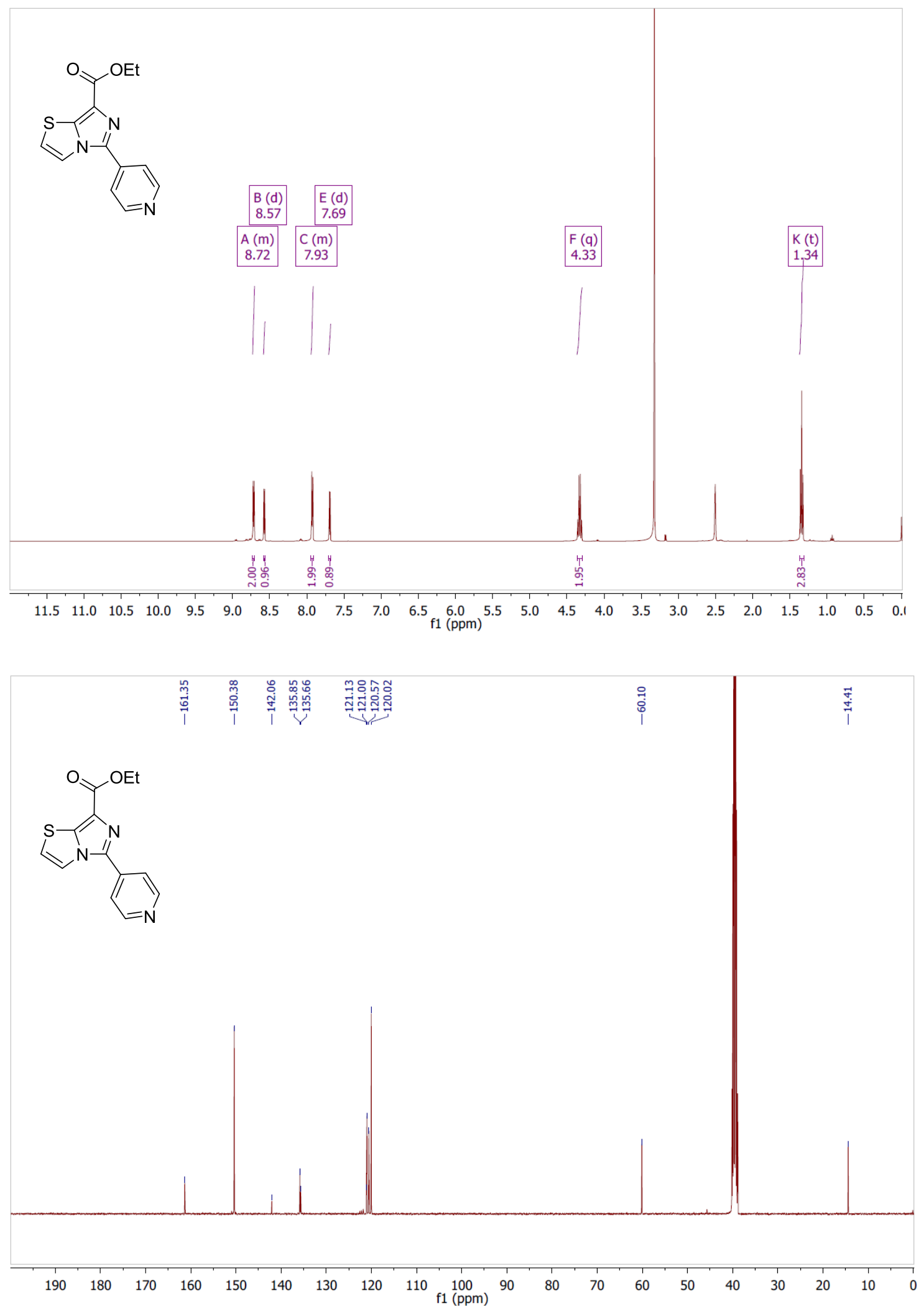


\section{Compound $3 j$}
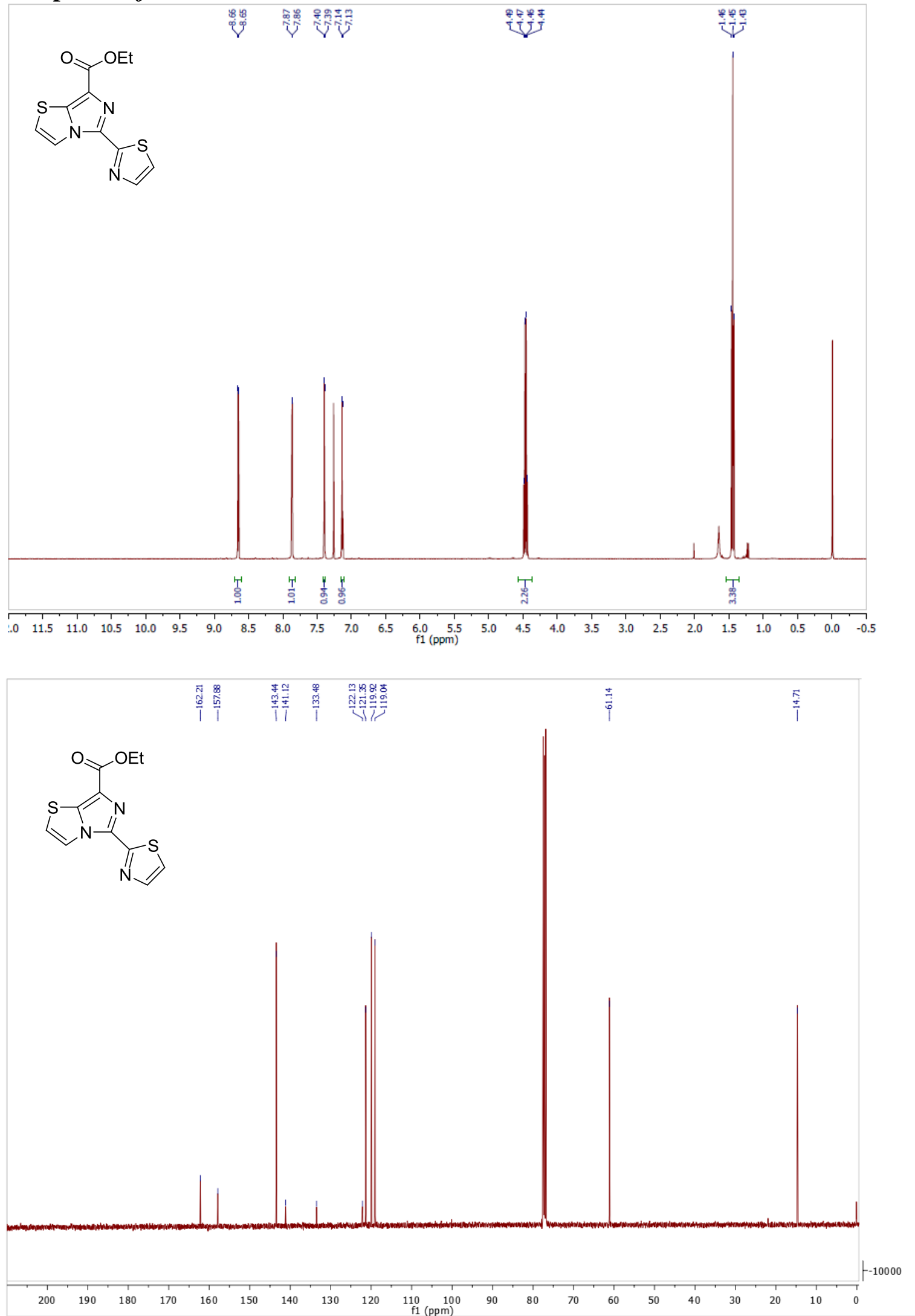


\section{Compound $3 k$}
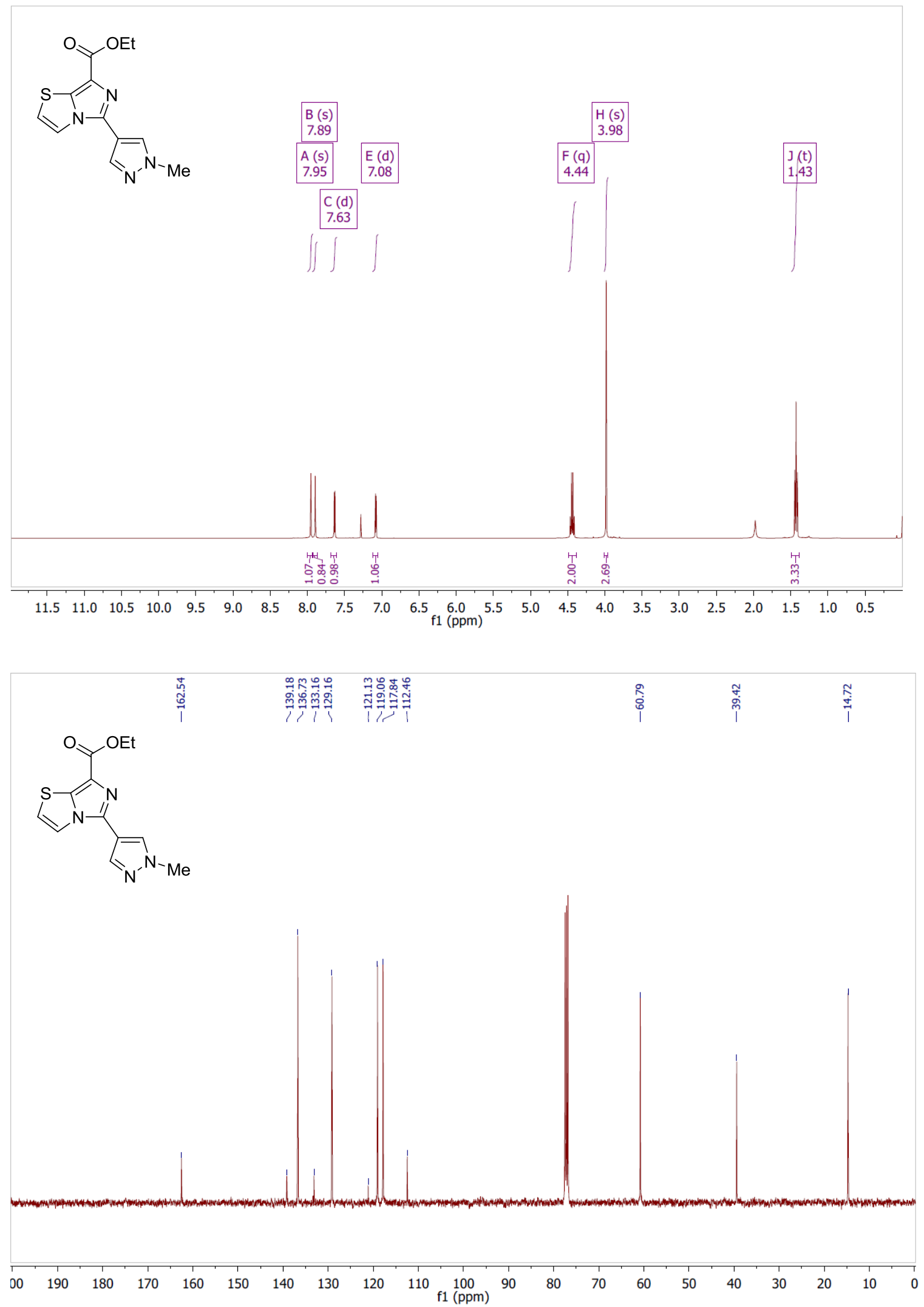


\section{Compound $3 l$}
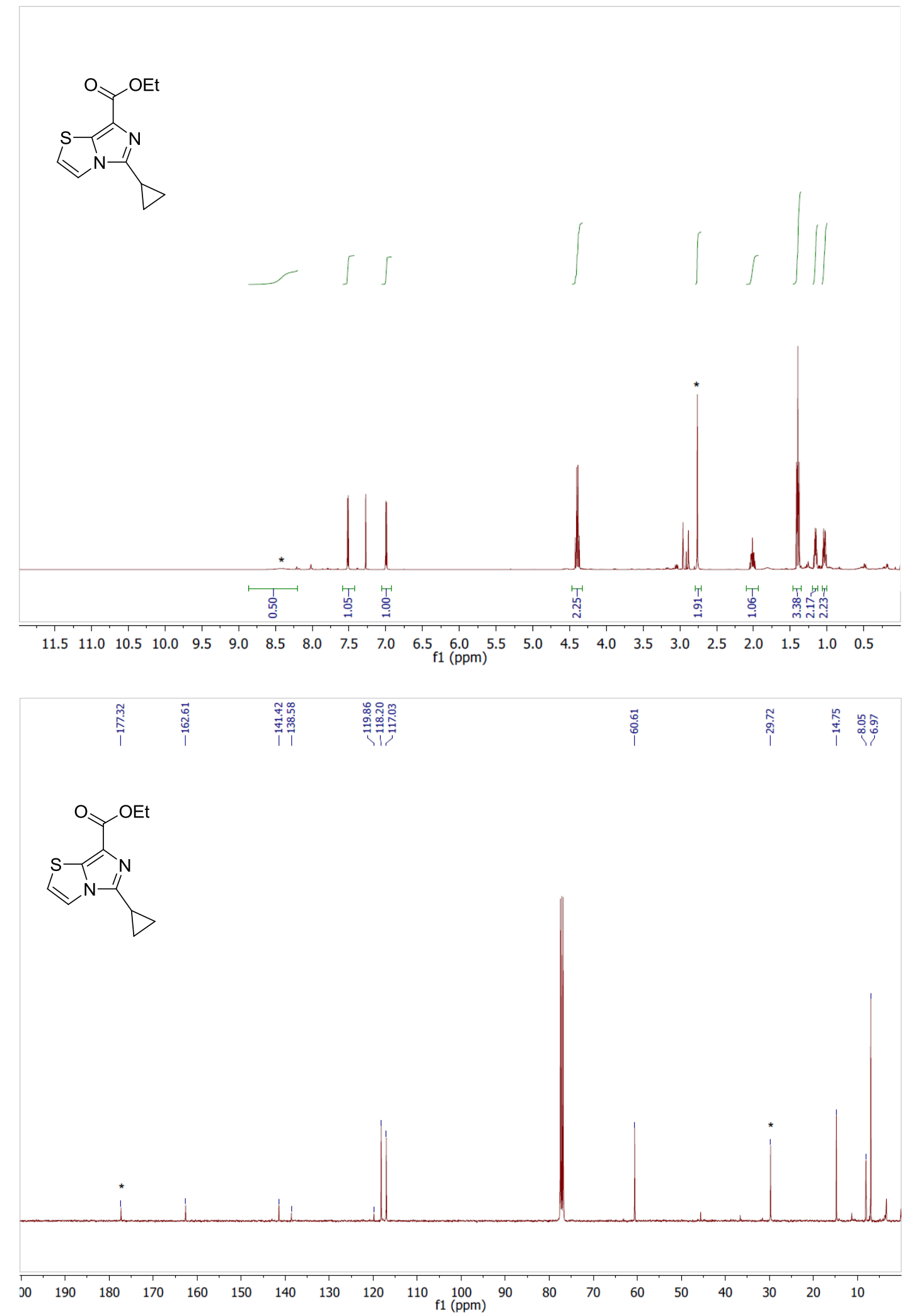


\section{Compound $3 m$}
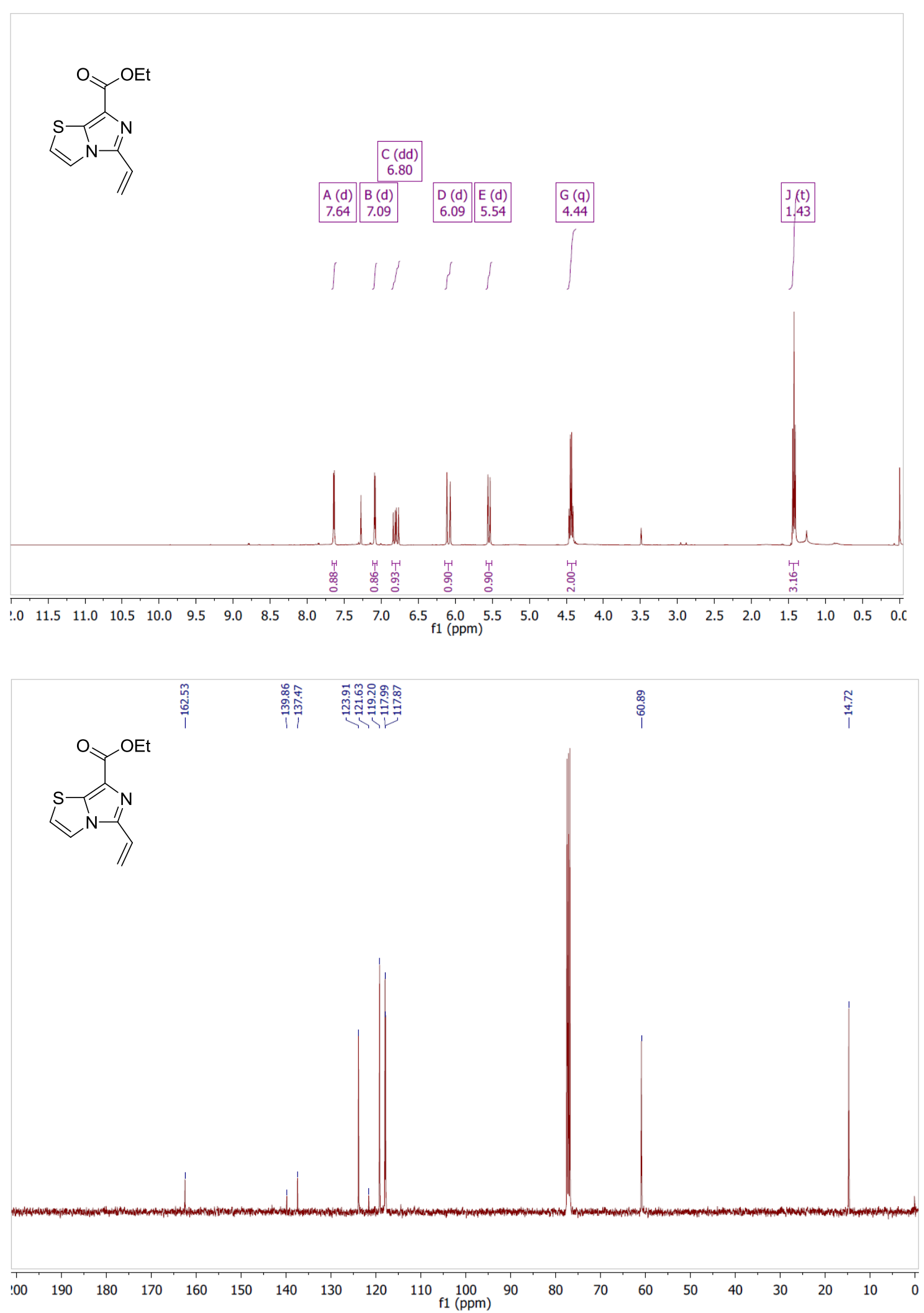


\section{Compound $4 b$}
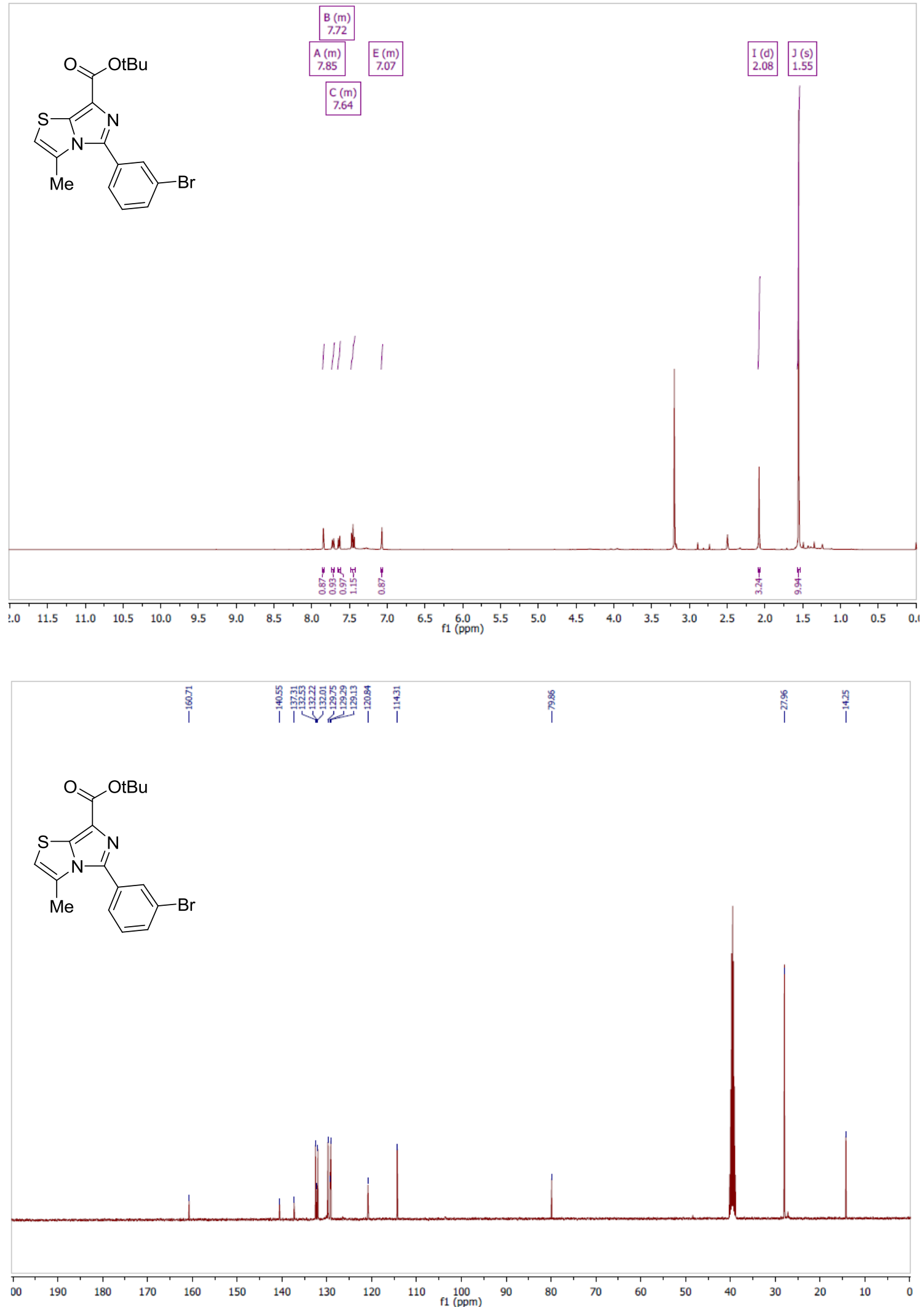


\section{Compound $4 c$}
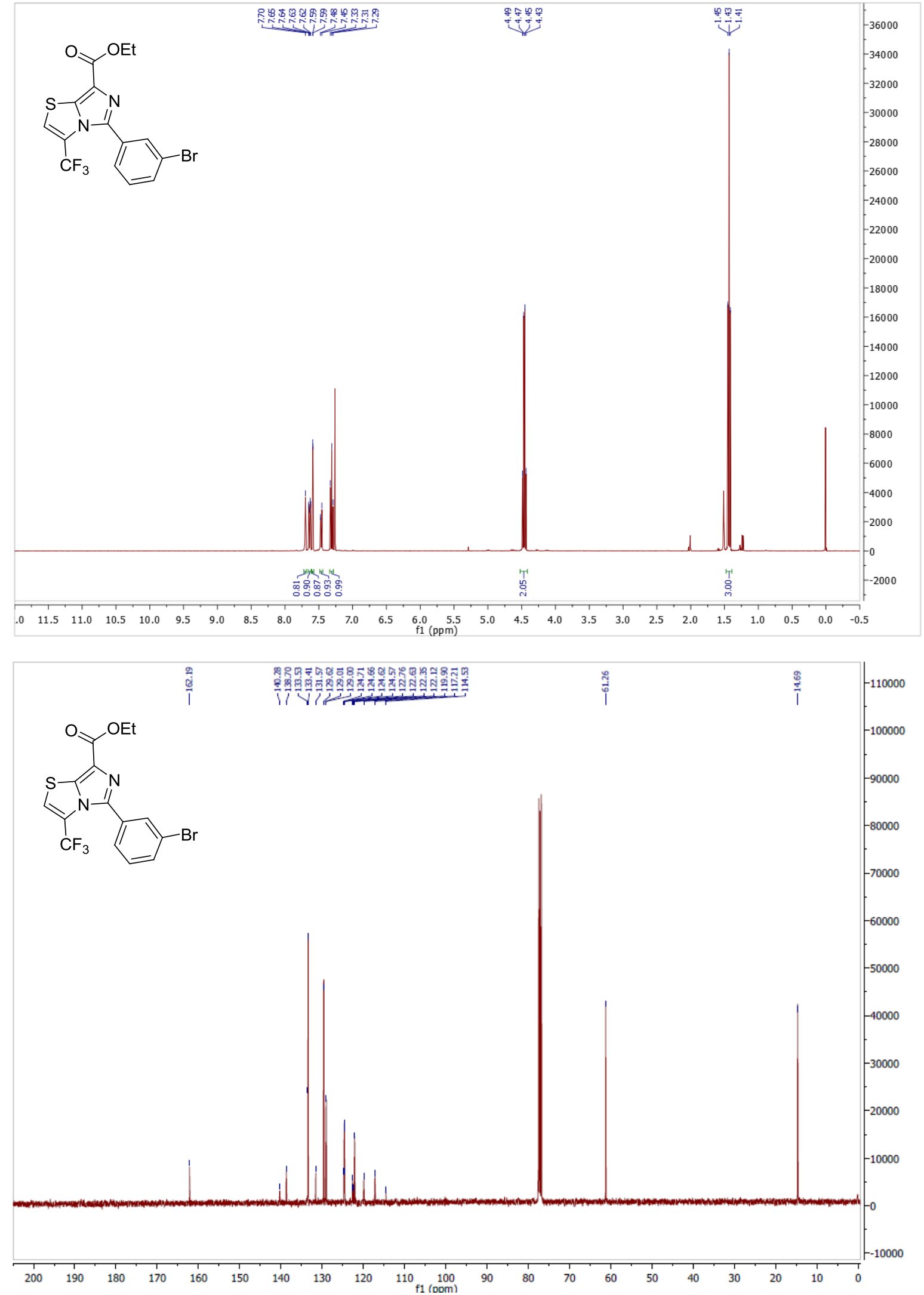


\section{Compound 4d}
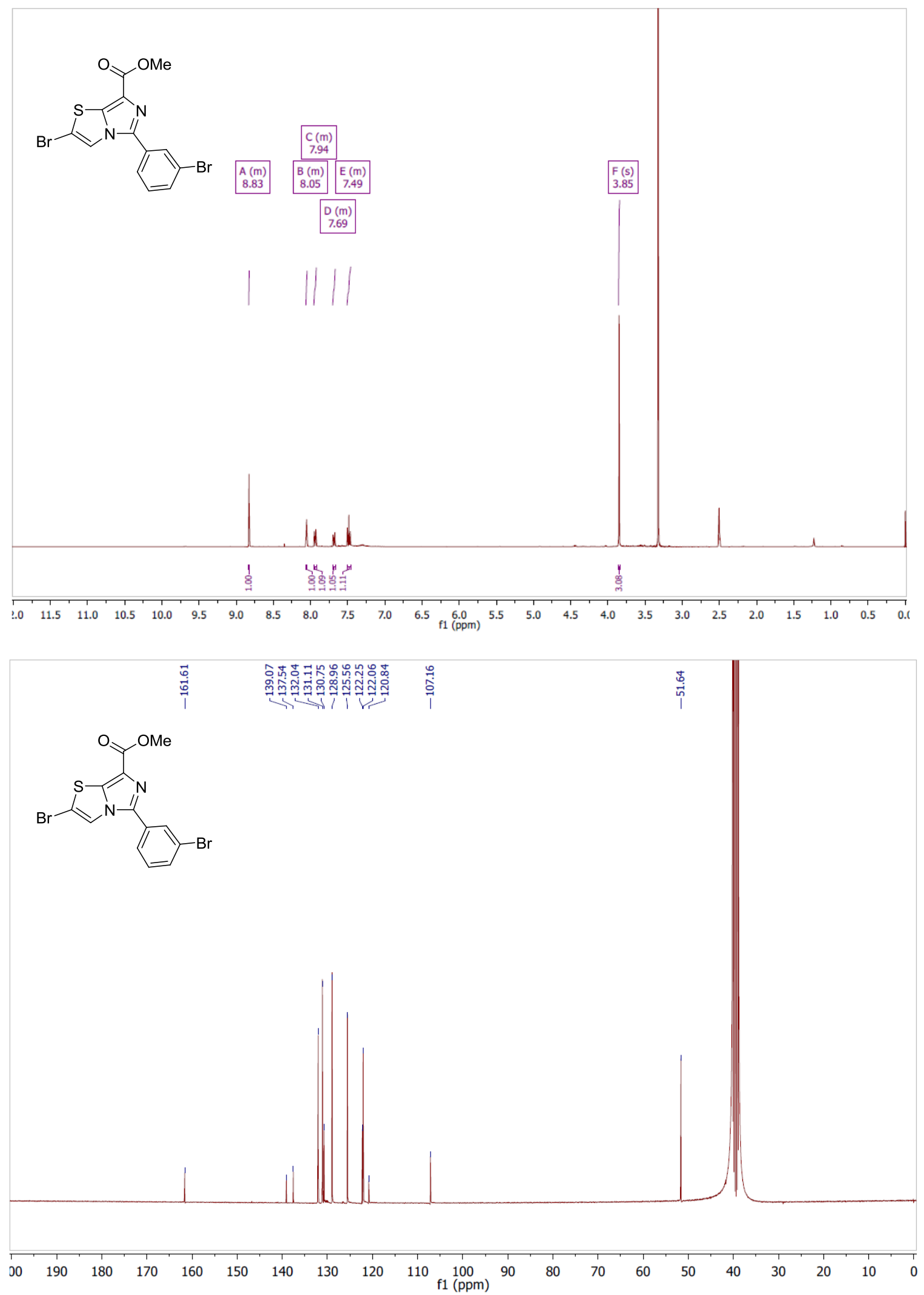


\section{Compound $4 e$}
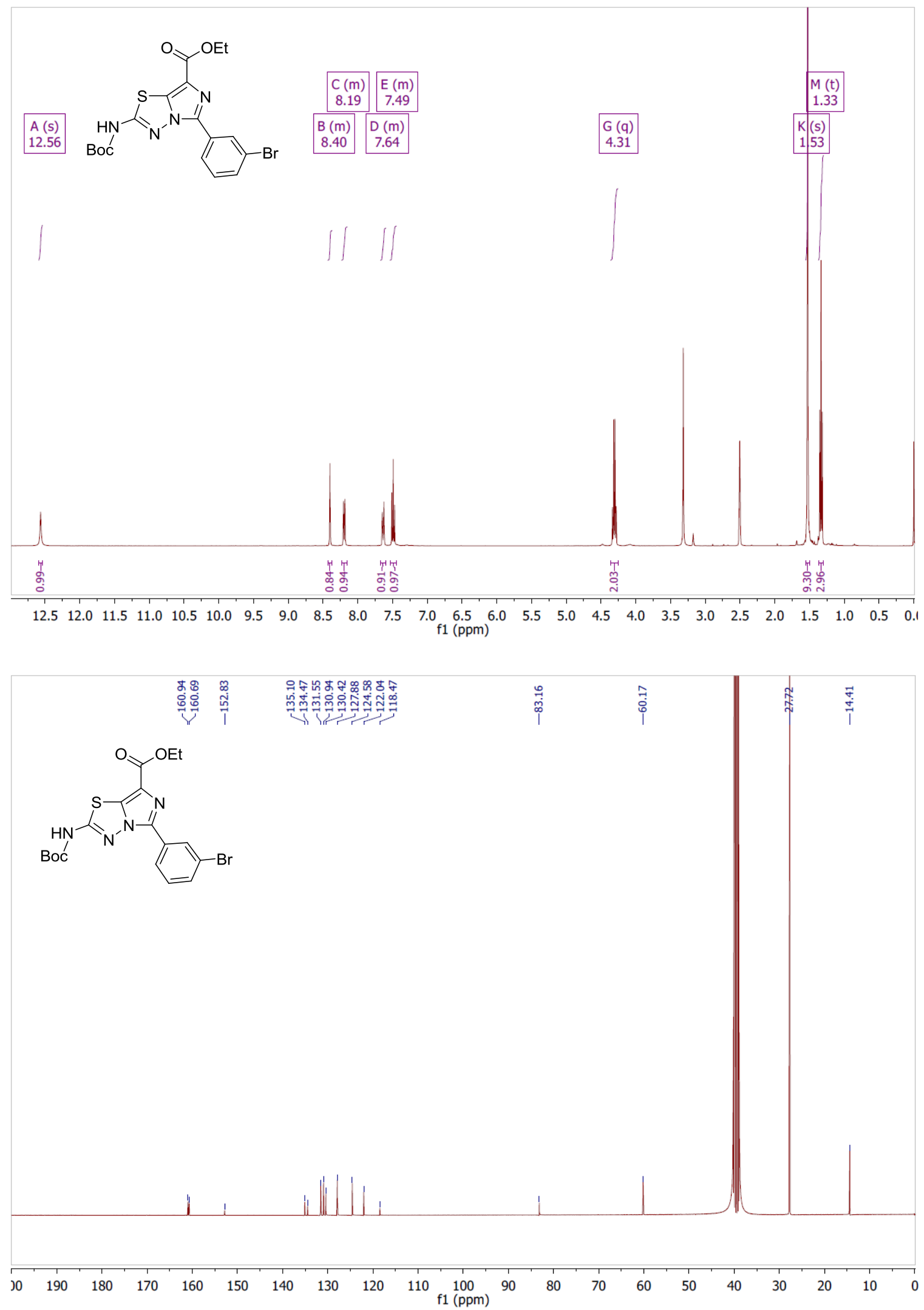


\section{Compound $4 f$}
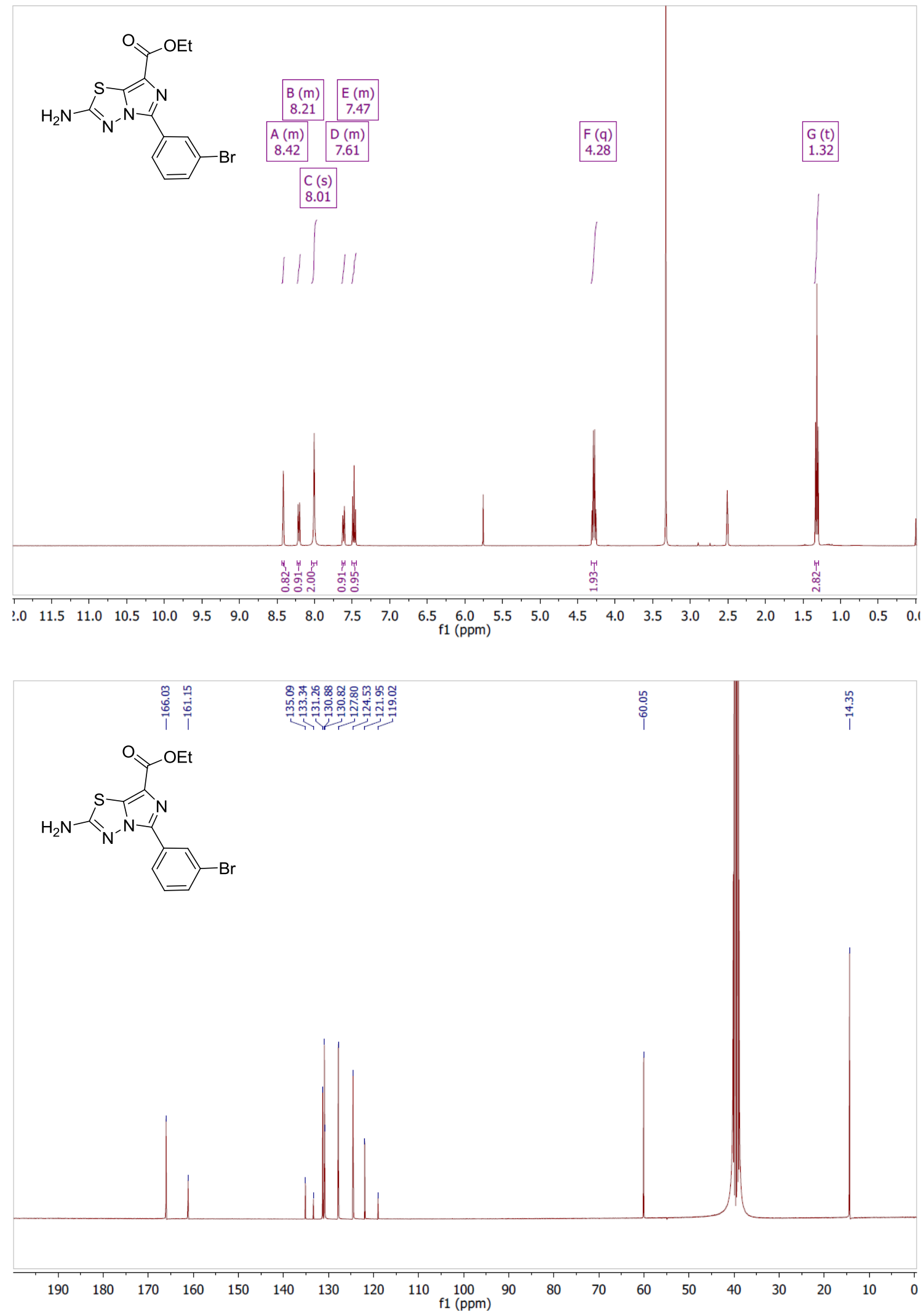


\section{Compound $4 g$}
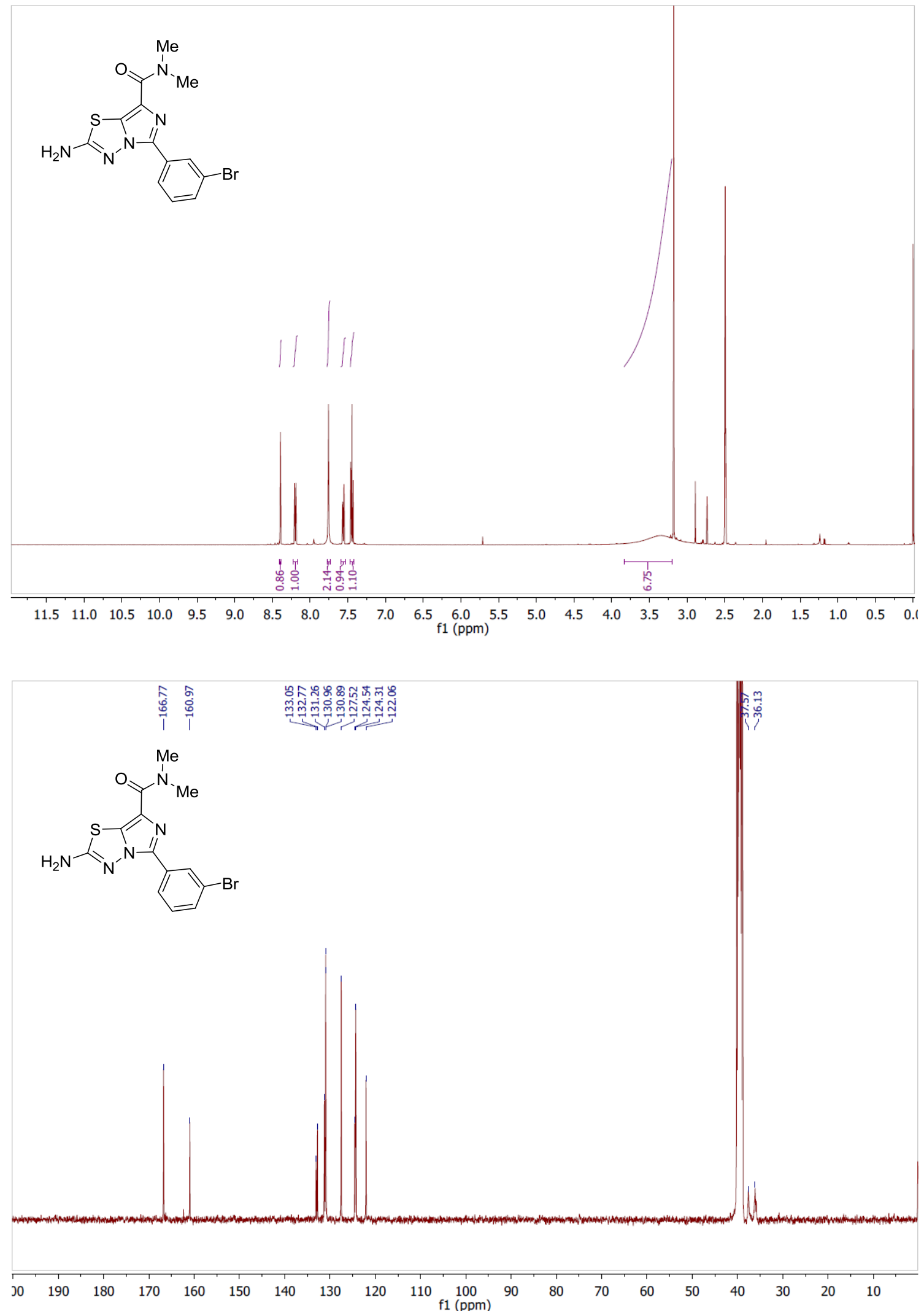


\section{Compound $4 h$}
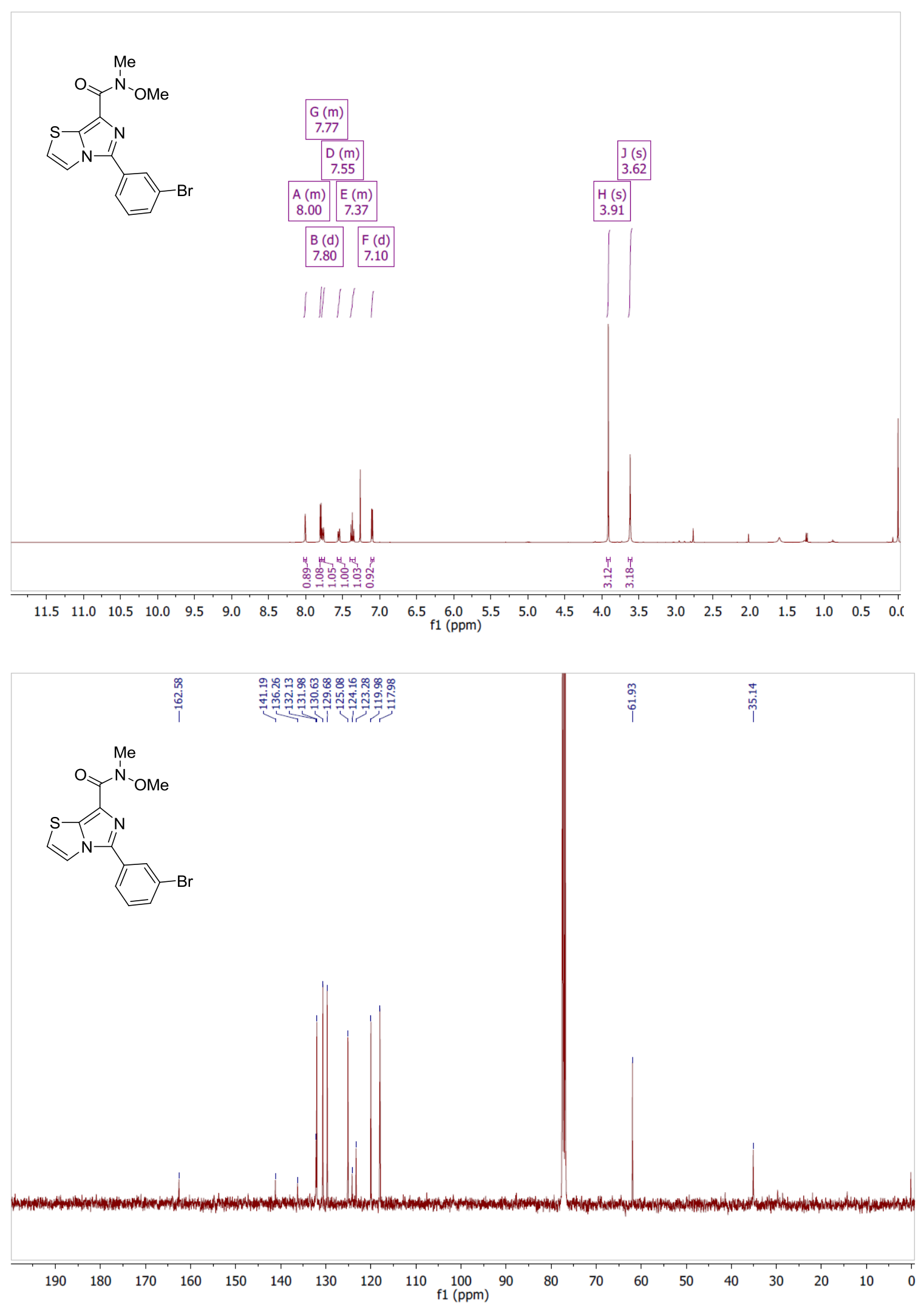


\section{Compound $4 i$}
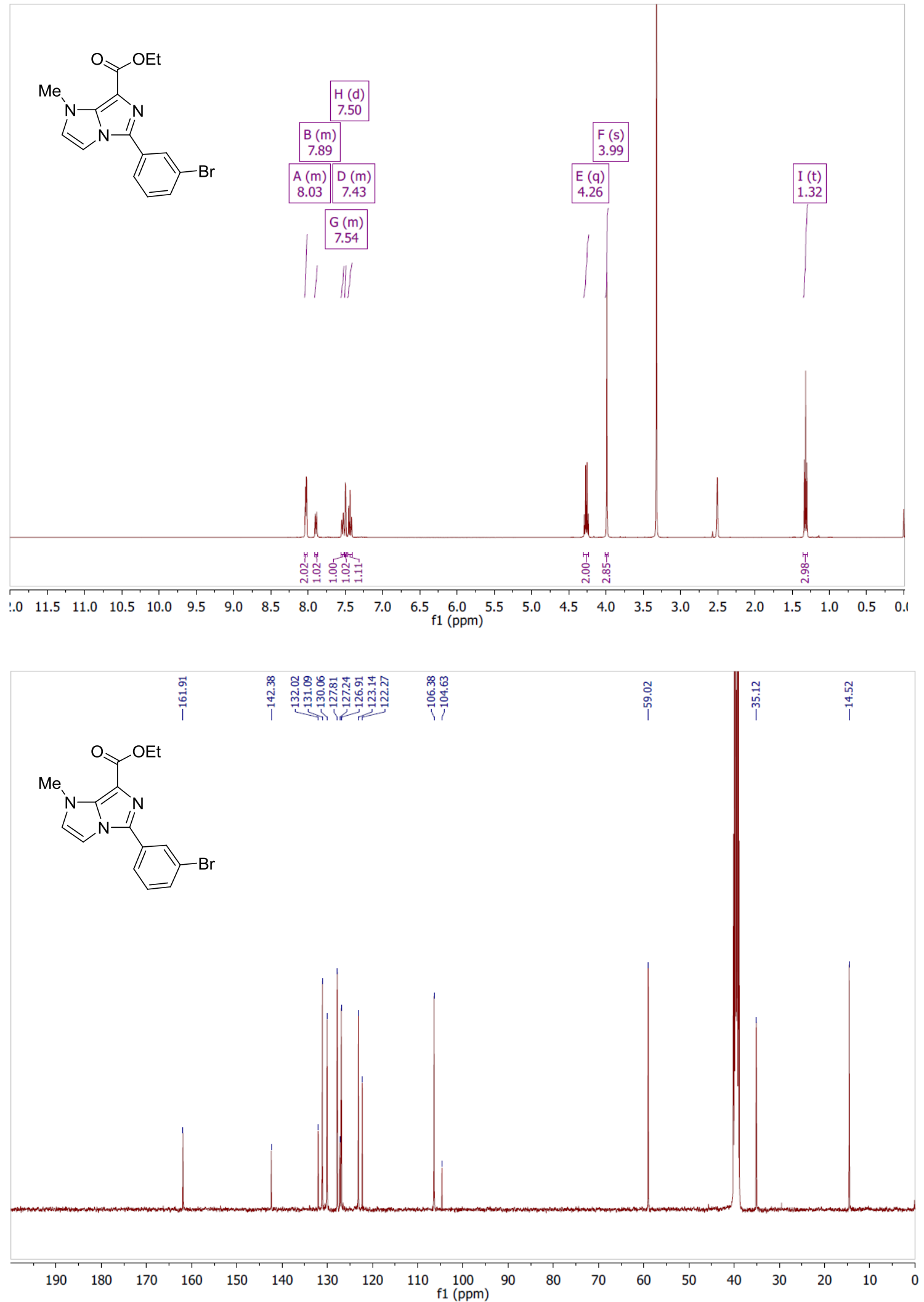


\section{Compound $4 j$}
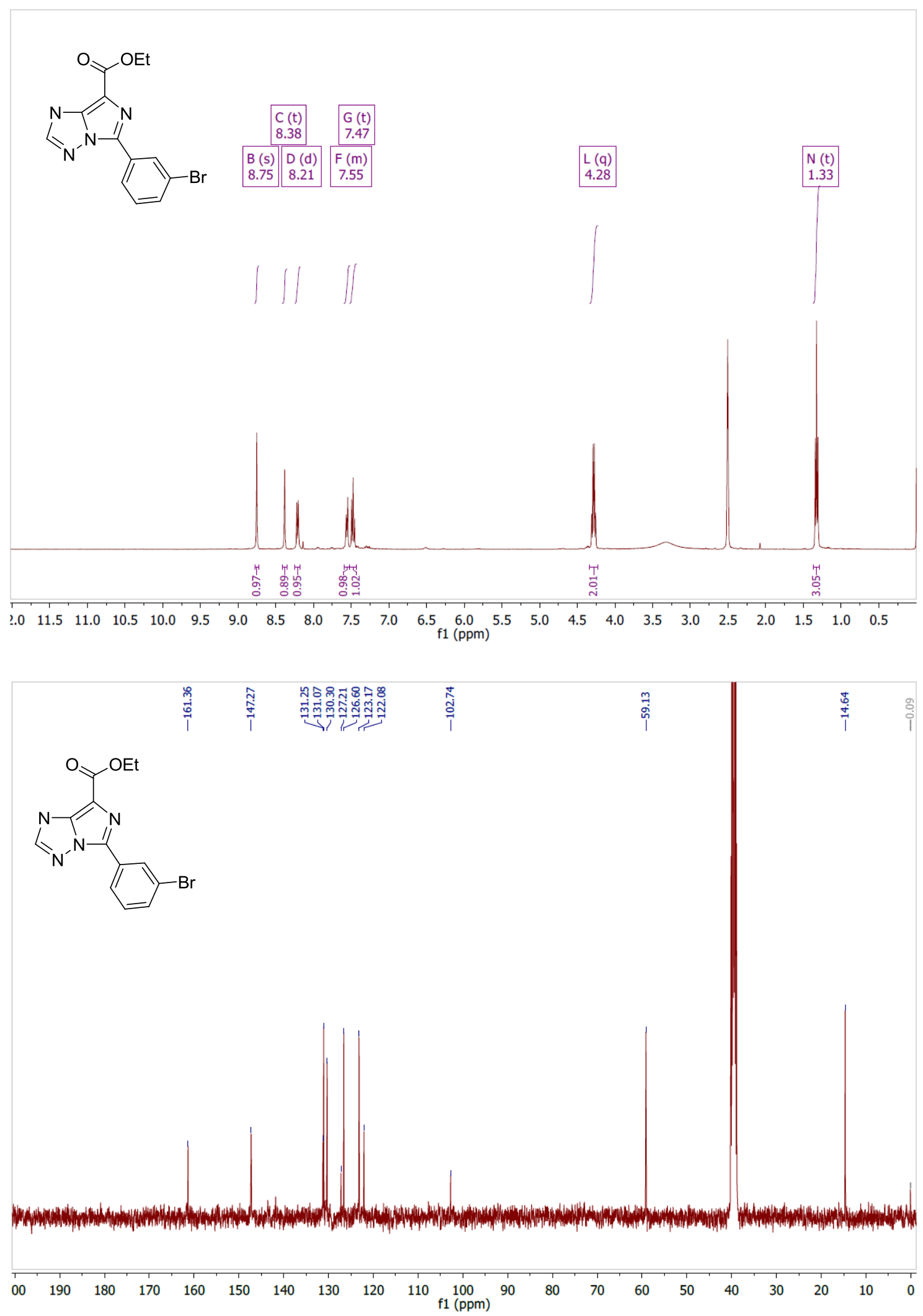


\section{Compound $4 k$}
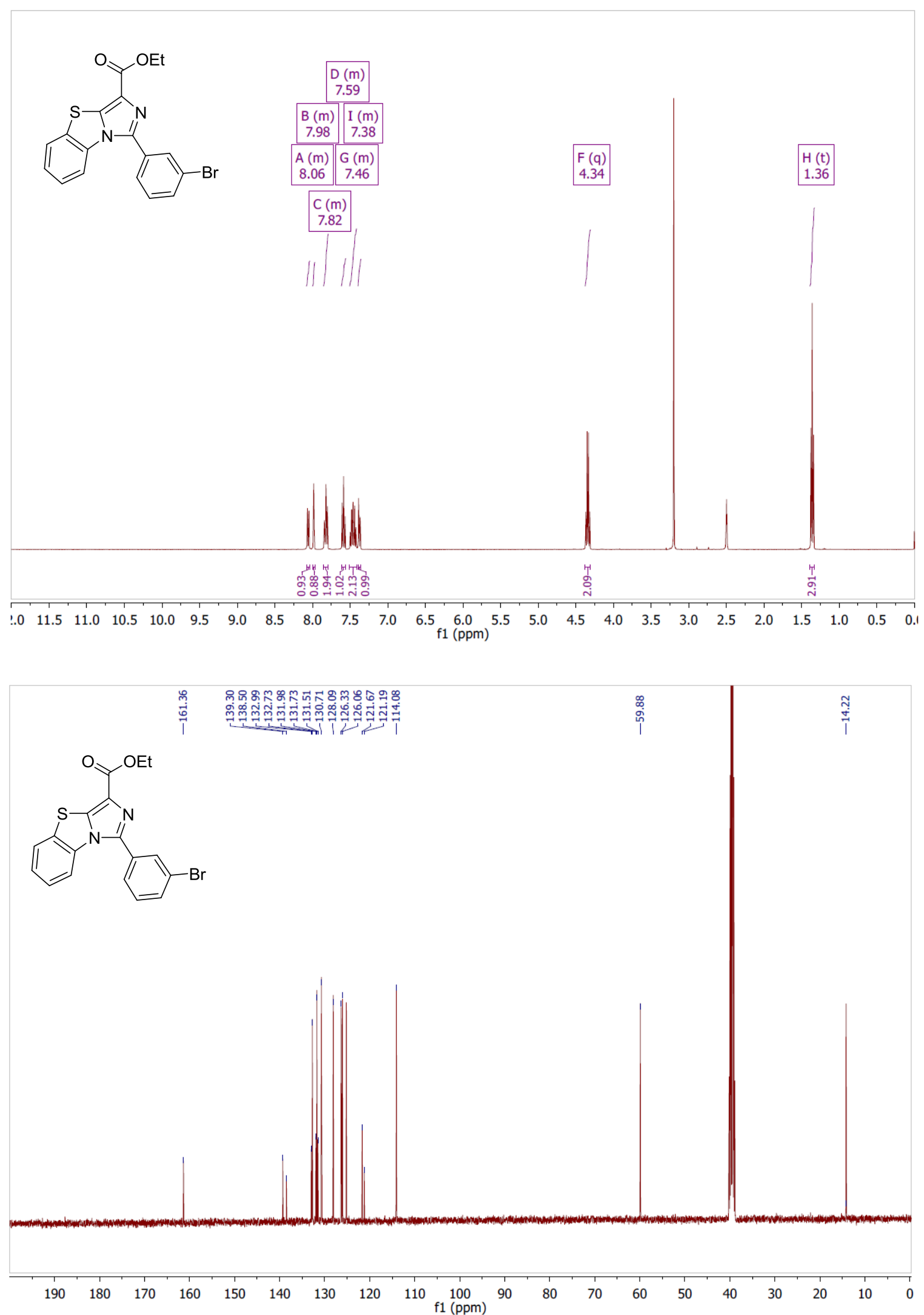


\section{Compound $4 l$}
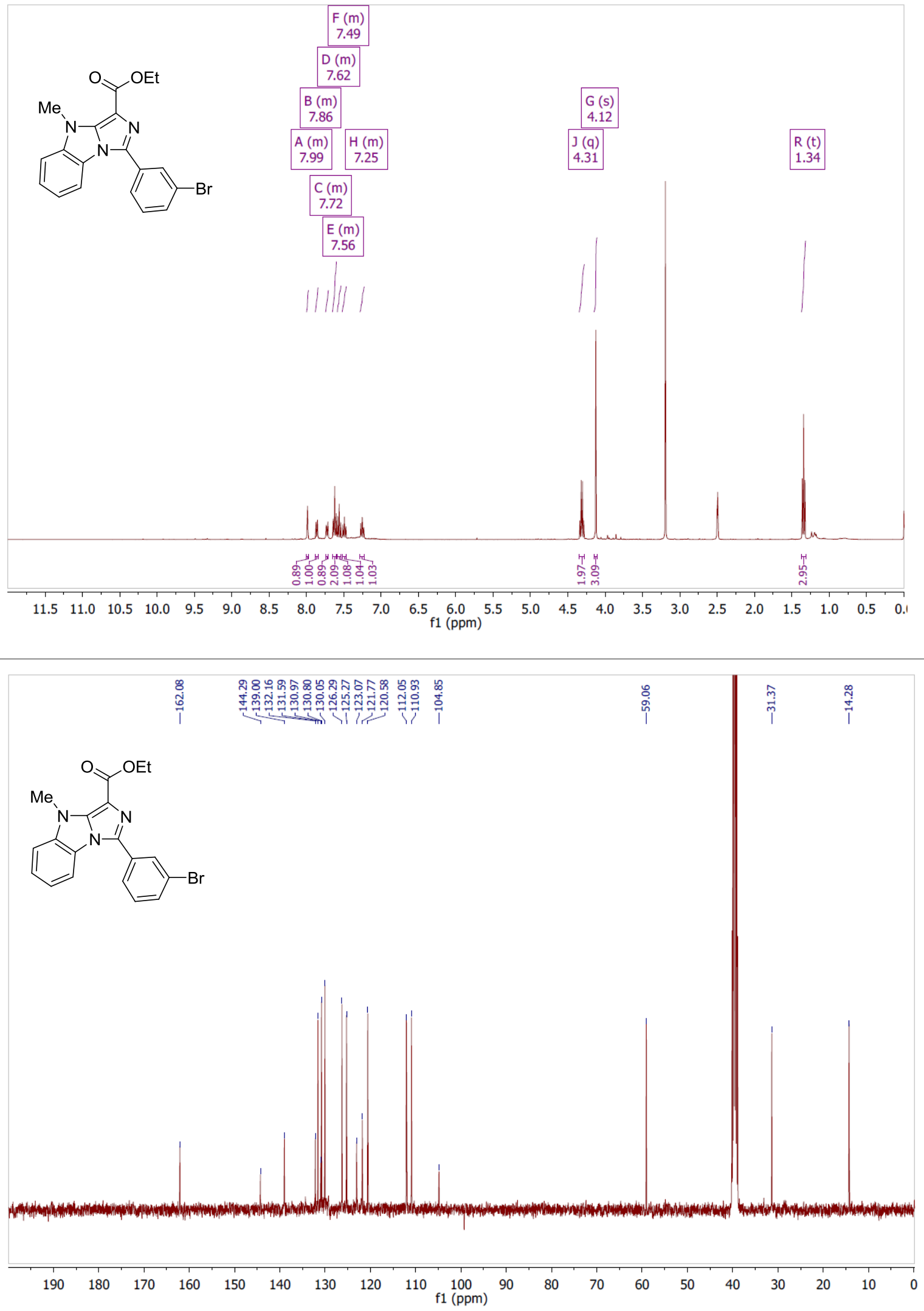


\section{Compound $4 m$}
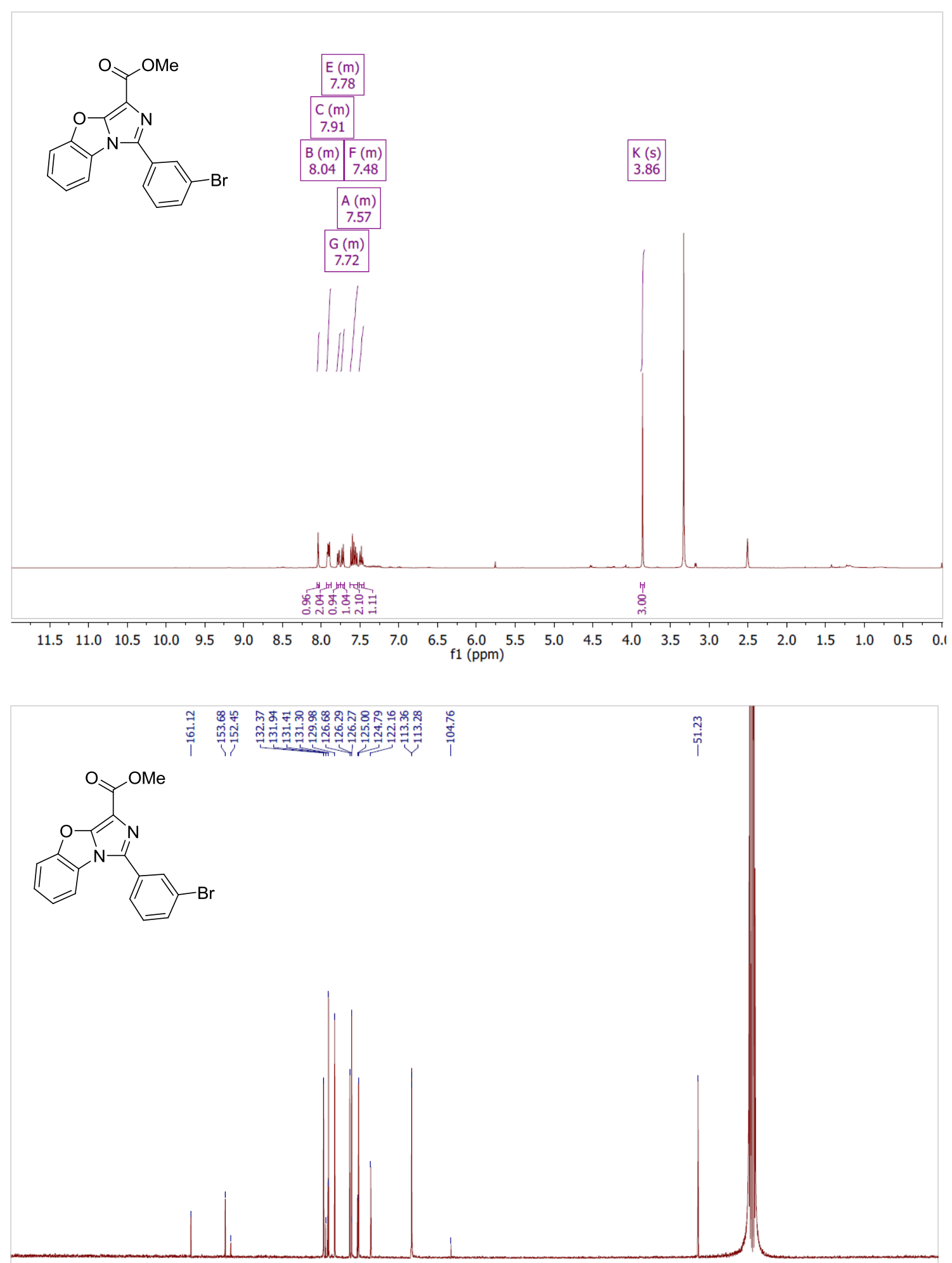

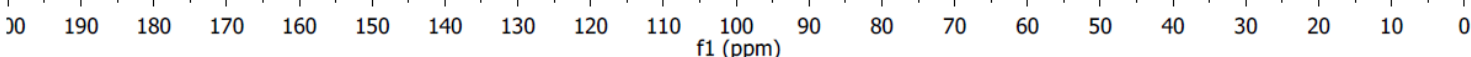




\section{Compound $4 n$}
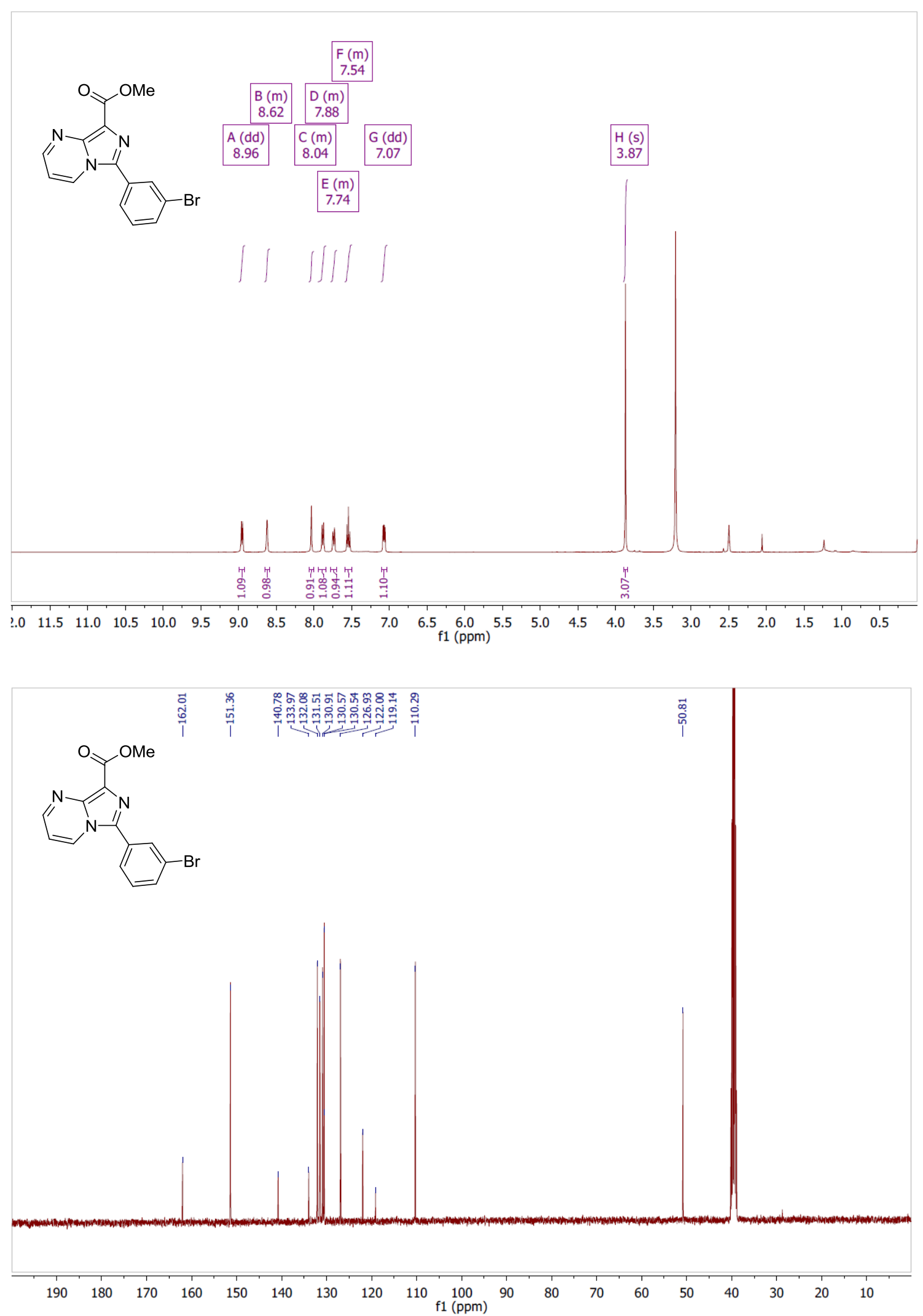


\section{Compound $4 o$}
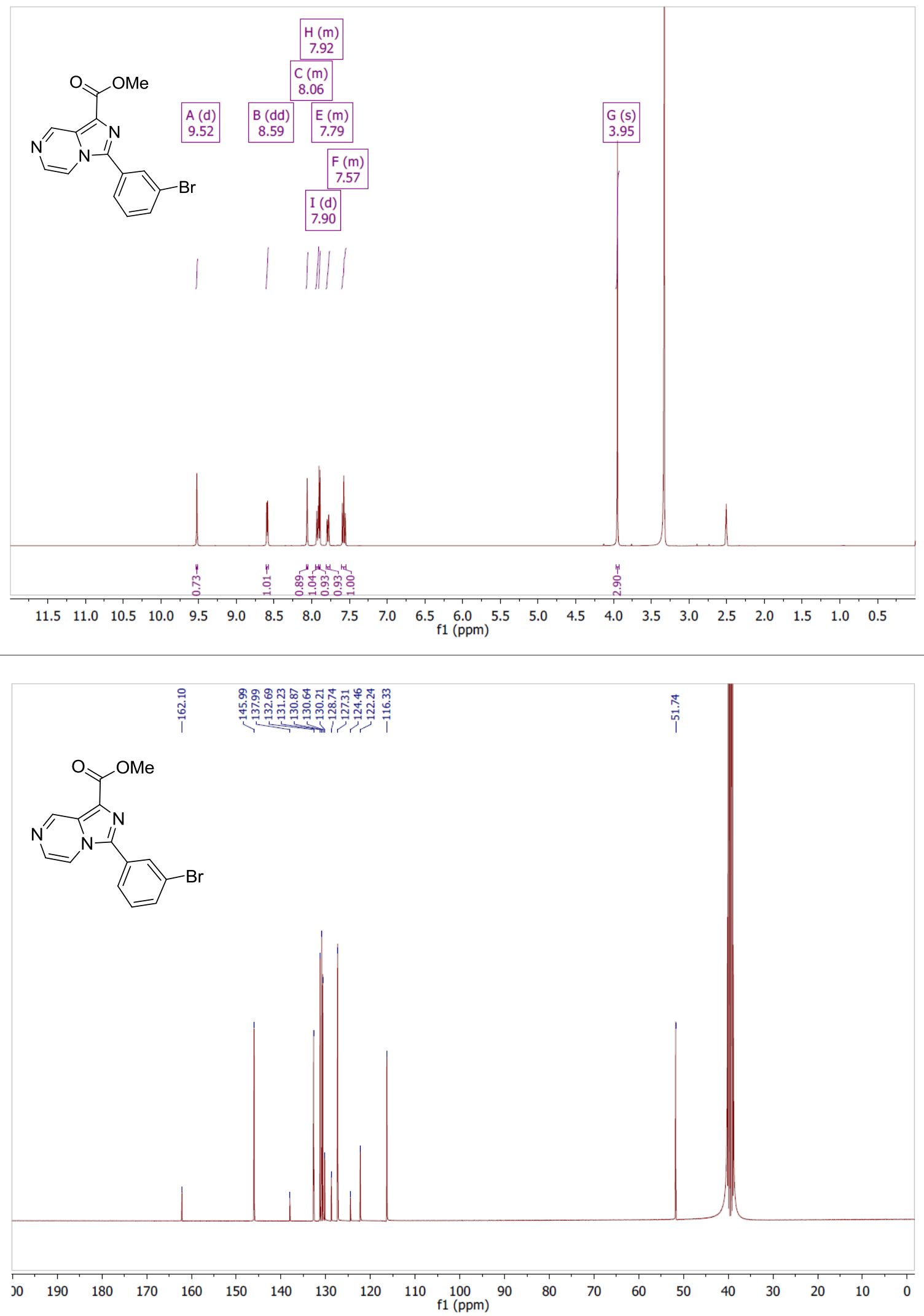


\section{Compound $4 p$}
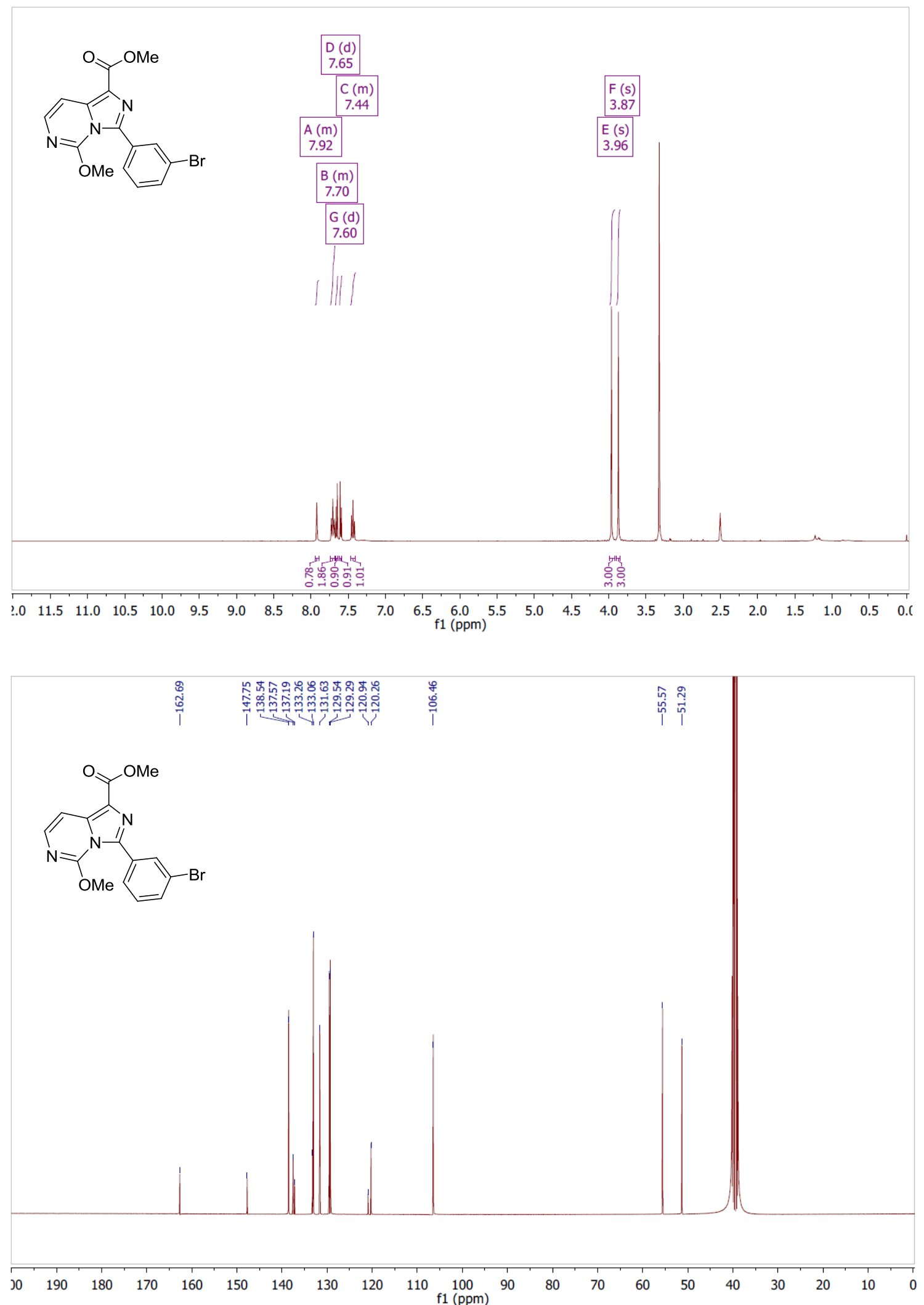


\section{Compound $4 q$}
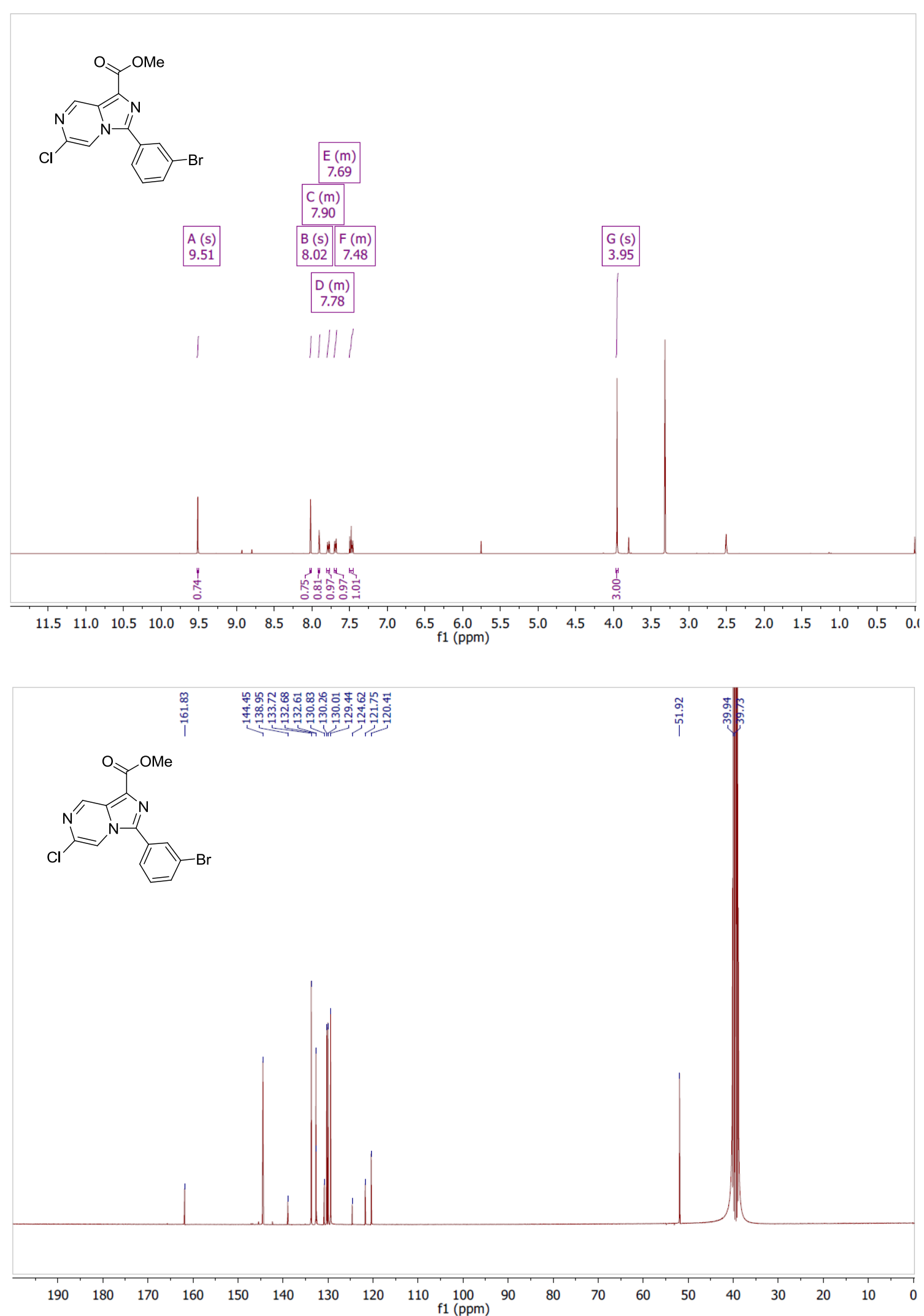


\section{Compound $4 r$}
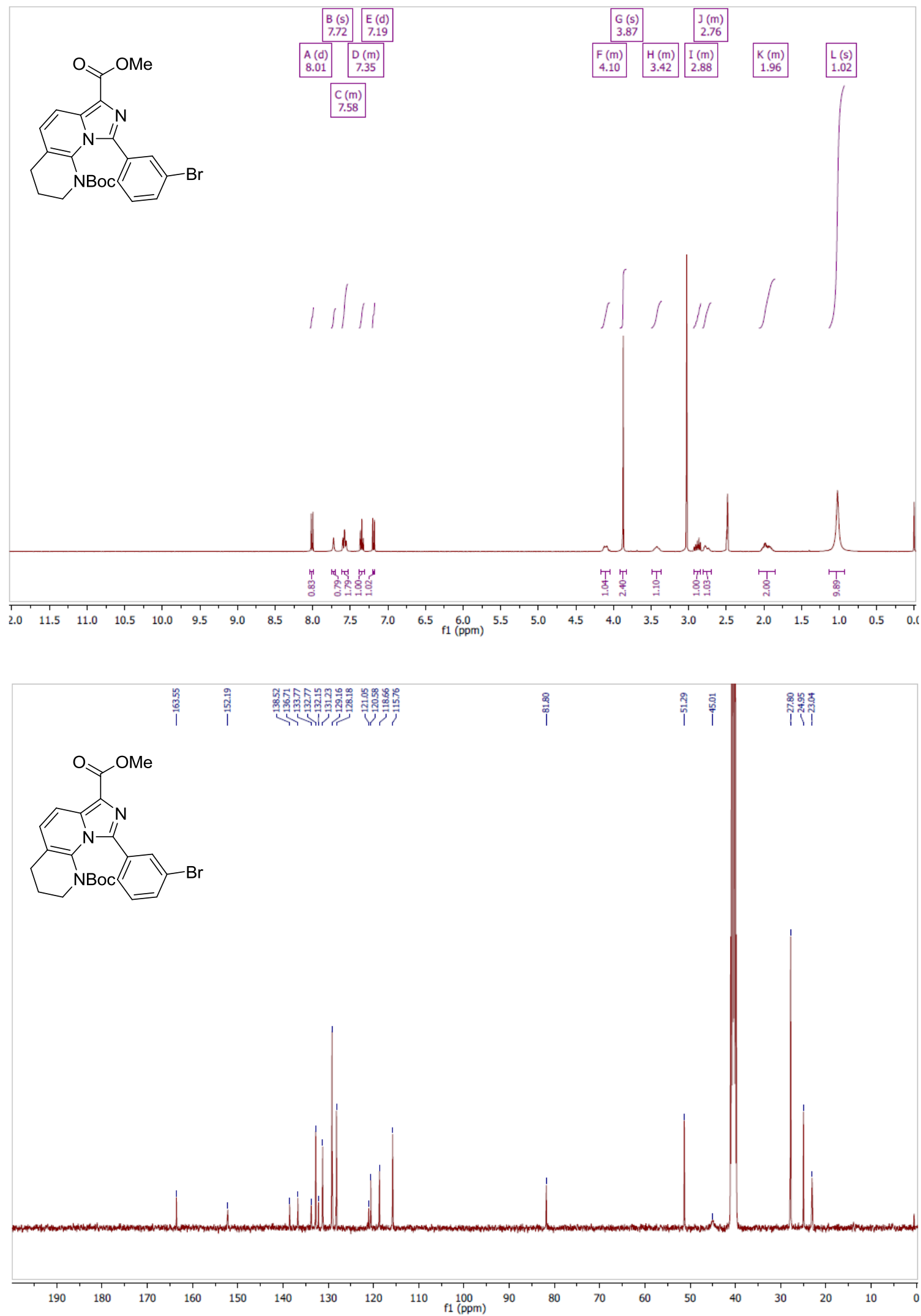
Compound $4 t$
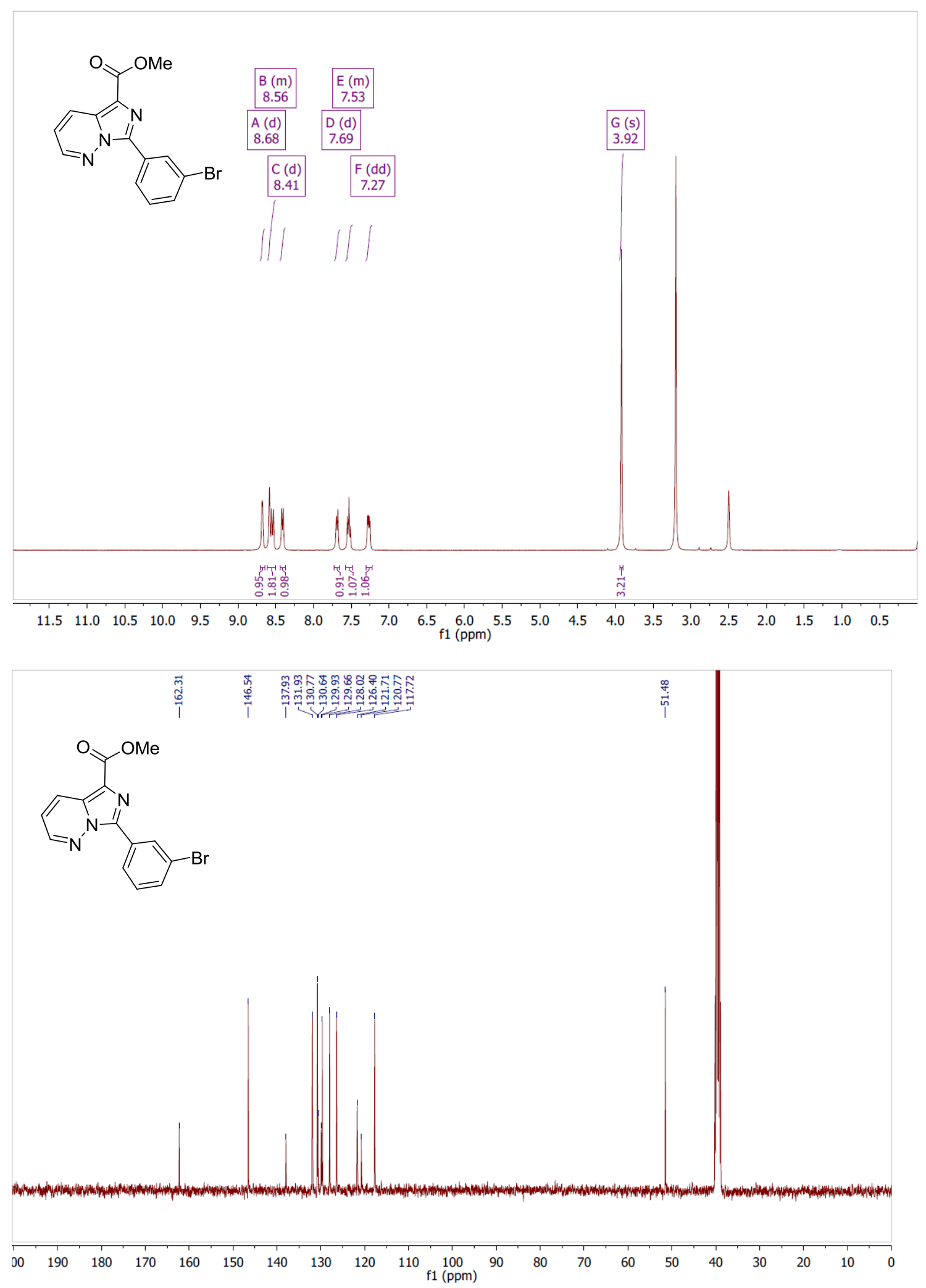

38 


\section{Compound 5}

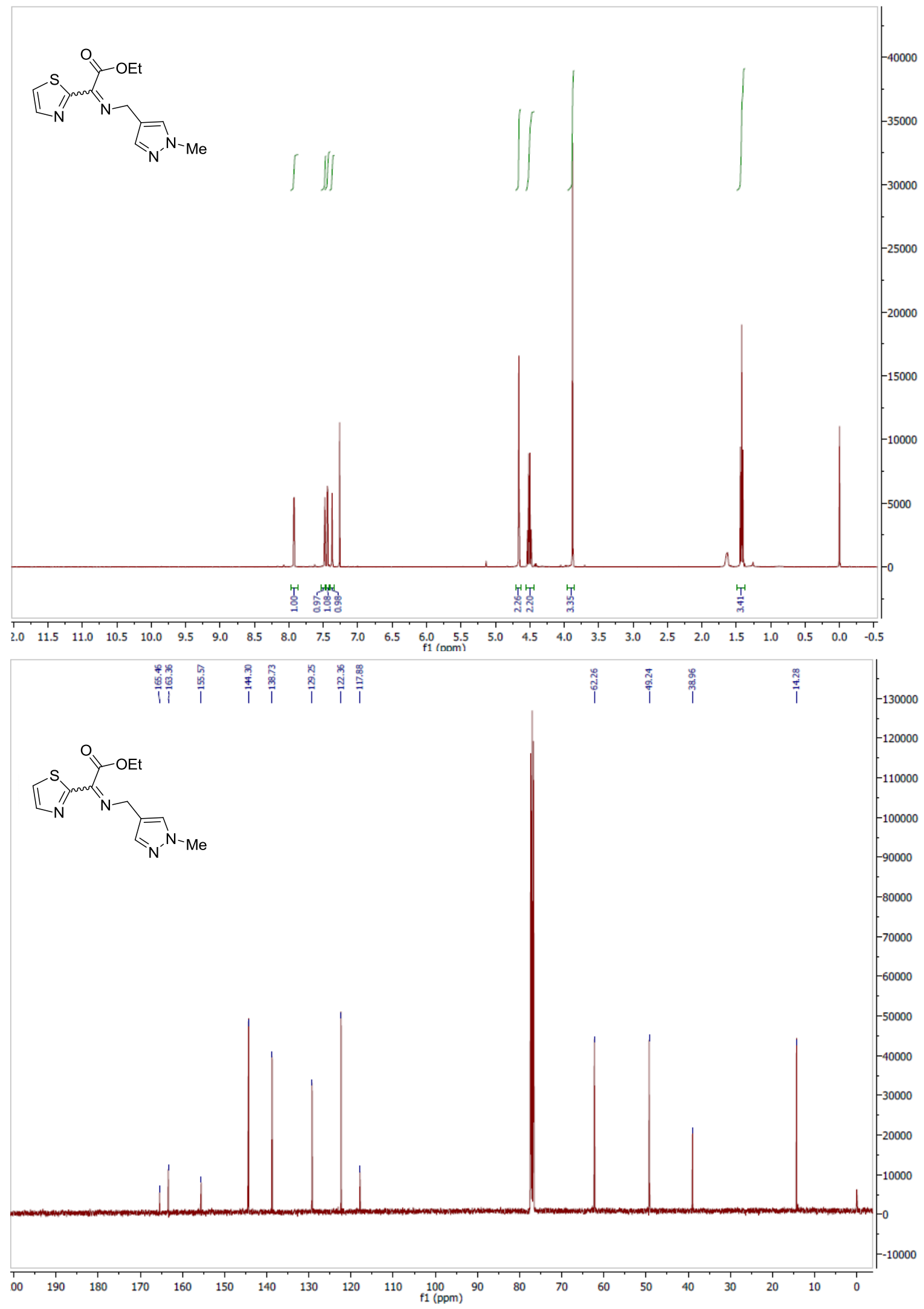




\section{Compound 6}
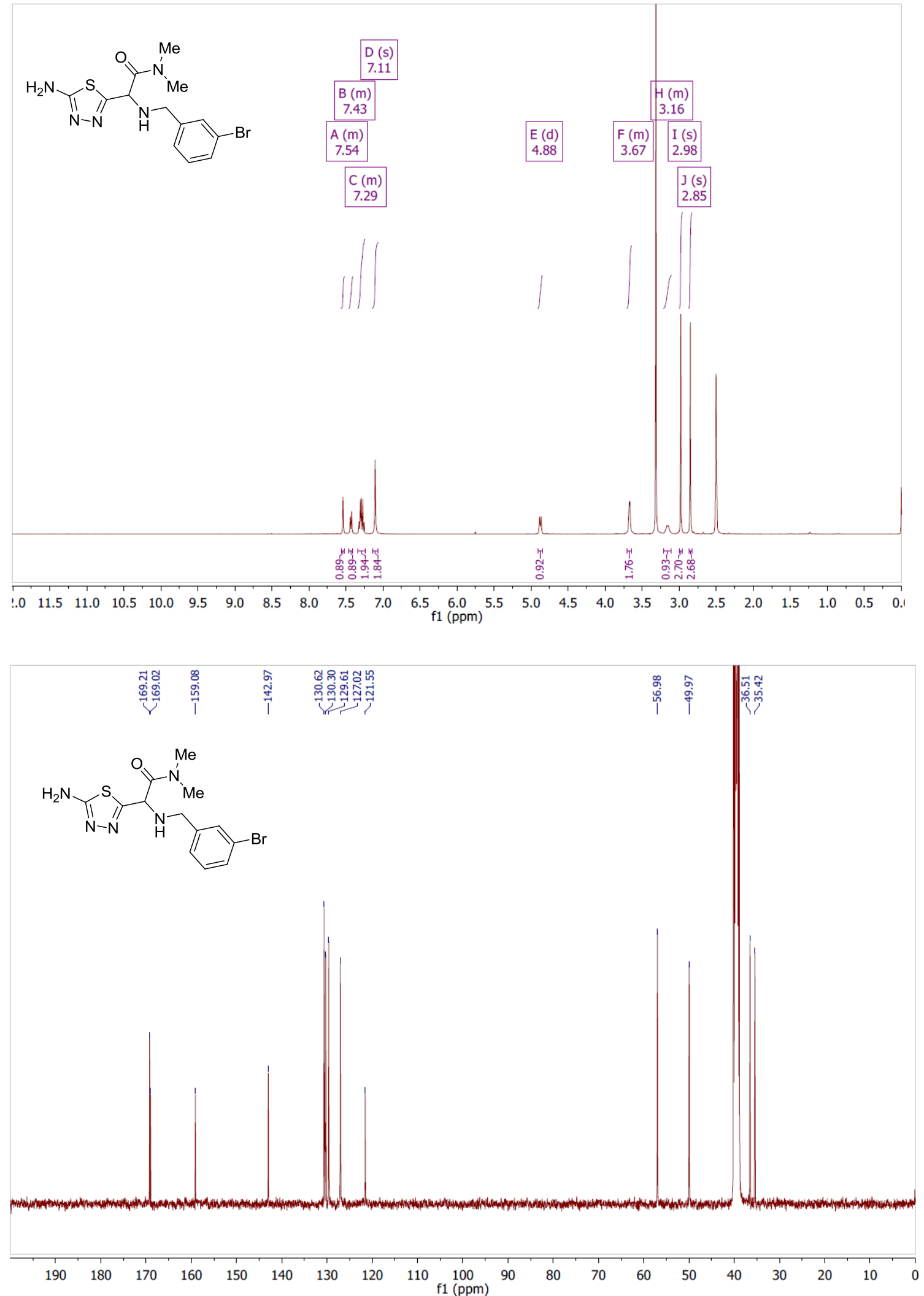


\section{Compound $4 u$}
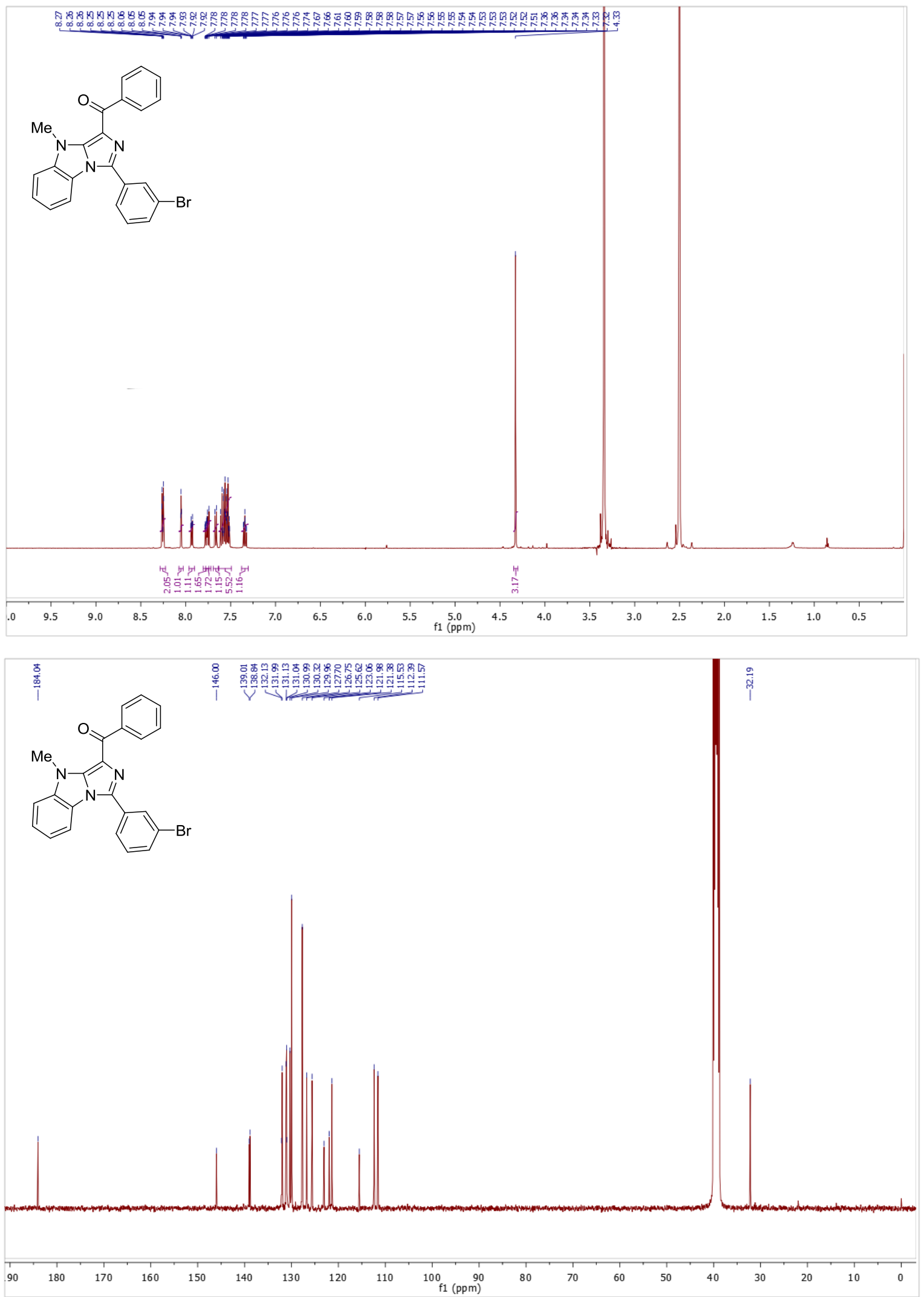


\section{Compound 7}
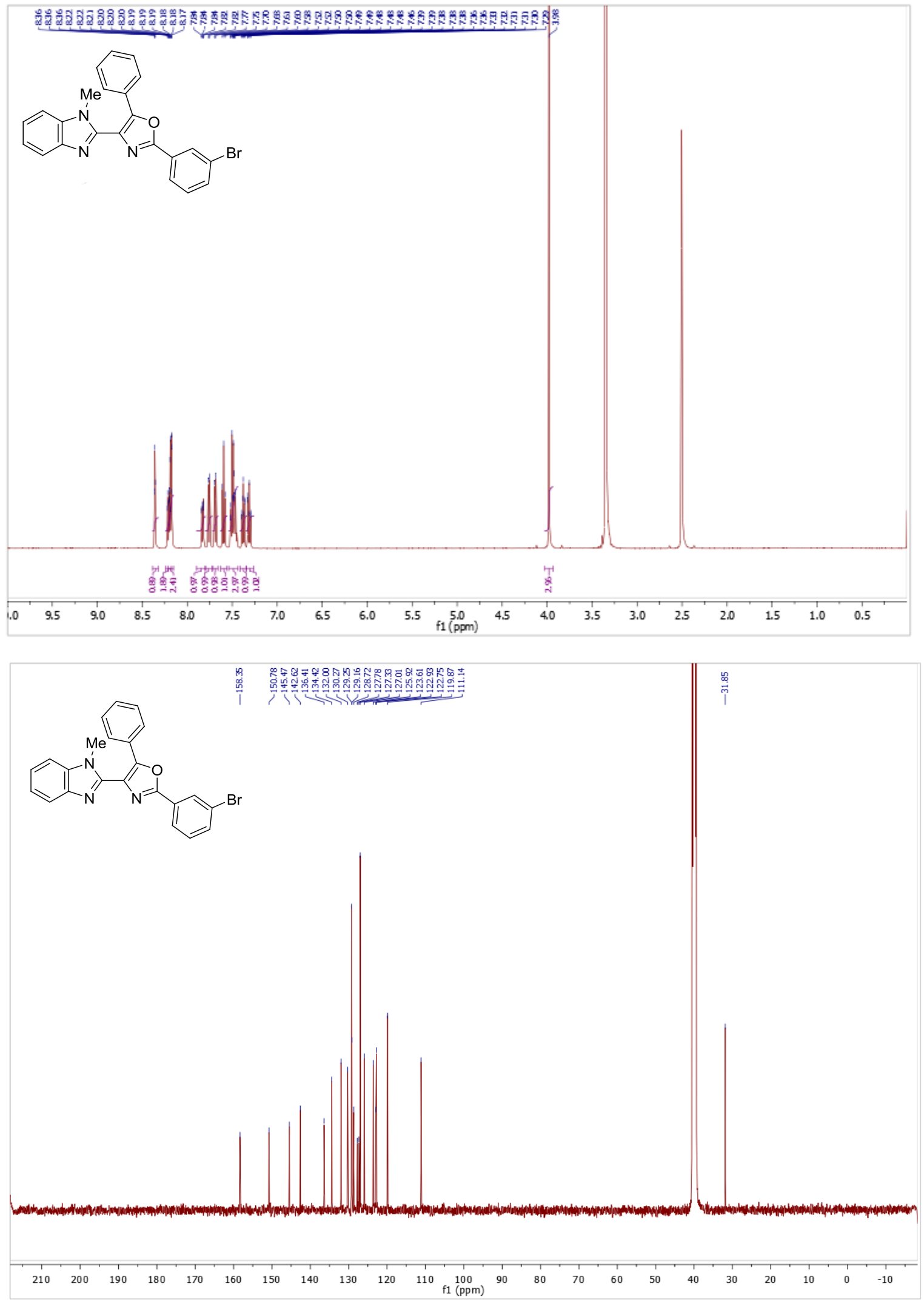


\section{Compound 8}
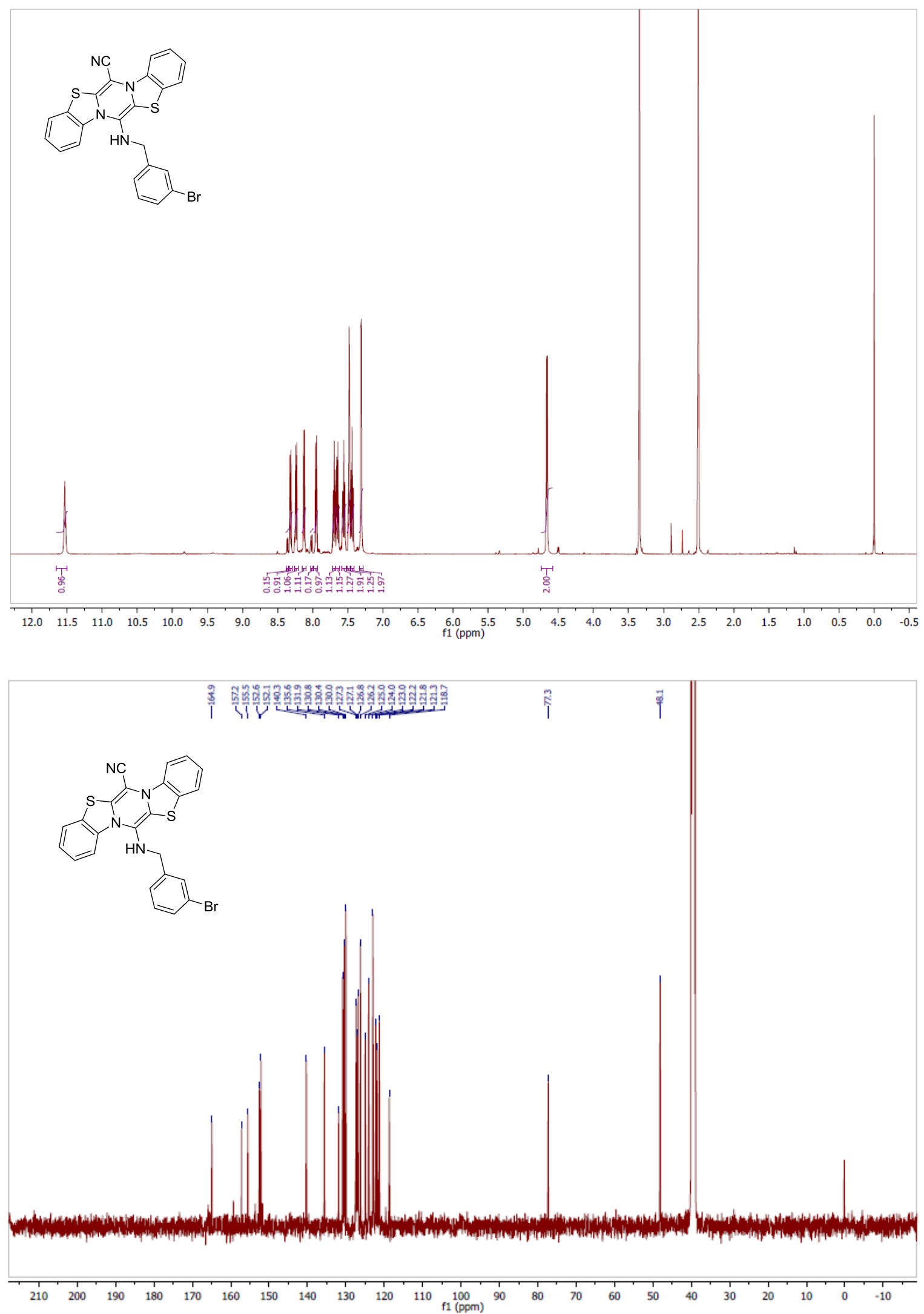